\title{
The Ebo-like running crab spiders in the Old World (Araneae, Philodromidae)
}

\author{
Christoph Muster \\ University of Greifswald, Zoological Institute and Museum, Germany \\ urn:lsid:zoobank.org:author:CEFD7C6B-440A-4896-992A-BD051E19A8BC \\ Corresponding author: Christoph Muster (muster@rz.uni-leipzig.de) \\ Academic editor: Jason Dunlop | Received 19 February 2009 | Accepted 26 April 2009 | Published 29 July 2009 \\ urn:lsid:zoobank.org:pub:6B4079A5-659D-490D-84E7-A4AF071EF091 \\ Citation: Muster C (2009) The Ebo-like running crab spiders in the Old World (Araneae, Philodromidae). In: Stoev P, \\ Dunlop J, Lazarov S (Eds) A life caught in a spider's web. Papers in arachnology in honour of Christo Deltshev. ZooKeys \\ 16: 47-73. doi: 10.3897/zookeys. 16.230
}

\begin{abstract}
A recent phylogenetic analysis within Philodromidae has shown that Ebo Keyserling, in its current limits, is a paraphyletic assemblage of spiders characterized by a strongly elongated second pair of legs and by enlarged anterior median eyes. Here a generic revision of Ebo-like philodromid spiders is provided, with the genera Ebo, Titanebo Gertsch (re-elevated to genus rank), Halodromus gen. n. and Philodromus Walckenaer ad. part. (the histrio species group = Rhysodromus Schick) being redefined and diagnosed. Ebo and Titanebo are Nearctic taxa whose occurrence in the Old World remains doubtful. Old World species with a long patellar apophysis on the male palp are included in Halodromus gen. n. (H. patellaris (Wunderlich, 1987), H. patellidens (Levy, 1977), both ex. Ebo). Three new species are described from both sexes, Halodromus barbarae sp. n. from the Arabian Peninsula, Egypt and Spain, H. deltshevi sp. n. from Yemen, and H. gershomi sp. n. from Eritrea. Ebo eremus Levy, 1999 is a new subjective synonym of Halodromus patellaris (Wunderlich, 1987). Halodromus is presumably an Afro-Syrian element with wide distribution in the Eremial of northern Africa and the Middle East. The Israeli species Philodromus halophilus (Levy, 1977), comb. n. ex. Ebo is transferred to the Philodromus histrio species group.
\end{abstract}

\section{Keywords}

Afroeremial region, generic revision, Halodromus, phylogeny, Rhysodromus, taxonomy, Titanebo

Copyright Christoph Muster. This is an open access article distributed under the terms of the Creative Commons Attribution License, which permits unrestricted use, distribution, and reproduction in any medium, provided the original author and source are credited. 


\section{Introduction}

Ebo is a diverse genus of philodromid spiders in North America (Keyserling 1884; Sauer and Platnick 1972). Their characteristic trait is the conspicuously elongated second pair of legs, which can be more than twice as long as the other legs. Further diagnostic characters include a flattened prosoma which is wider than long or as wide as long, and the eye configuration: AME (anterior median eyes) are distinctly larger than the other eyes, both rows slightly recurved, medians of both rows closer to the laterals than to each other (Schick 1965; Sauer and Platnick 1972; Levy 1977). Based on this set of characters, Tikader (1965), Levy (1977, 1999), Wunderlich (1987) and Lyakhov (1992) included new Philodromidae from India, Israel, the Canary Islands and the mountains of South Siberia in Ebo. However, even a loose examination of the genital traits (cf. Fig. 1 versus Figs 2, 3) shows that the Old World Ebo species have little in common with the Nearctic representatives. Furthermore, the above mentioned combination of characters is also found in other taxa of Philodromidae, e.g. in most species of the Philodromus histrio group (Dondale and Redner 1975; Szita and Logunov 2008). Thus, it seems that elongation of leg II and enlargement of the AME coevolved independently several times within the family, and Ebo apparently became a paraphyletic taxon through inclusion of the Old World species. This view is corroborated by a thorough examination of the leg spination pattern. Recent comprehensive studies within Philodromidae have shown that leg spination, in particular that of the tibiae and metatarsi, is presumably the most useful morphological criterion for delineation of supraspecific taxa in this family (Muster 2009). Concerning leg spination in Ebo, I found not only the Old World species to be more similar to spiders of the Philodromus histrio group (= Rhysodromus Schick, 1965) than to North American congeners, but also striking differences between the Nearctic subgenera Ebo and Titanebo Gertsch, 1933. A first quantitative cladistic analysis of phylogenetic relationships within Philodromidae (Muster 2009) provided further evidence: Ebo emerged as the most basal clade within the family, while Titanebo grouped with Rhysodromus, Old World Ebo and the Thanatini in a clade that was sister to the remaining Philodromus species. The aim of this study is a generic revision of the Ebo-like philodromid spiders (those with markedly elongated leg II and enlarged AME) in order to achieve a better concordance of genera with phylogenetic lineages. A group of Old World species with an elongated apophysis at the patella of the male palp is described as a new genus Halodromus gen. n. A taxonomic revision of the included species is provided.

\section{Material and methods}

Material from the following institutions and private collections was examined (institutional abbreviations follow Evenhuis 2007):
AMNH American Museum of Natural History, New York
CB Coll. Robert Bosmans, Gent 


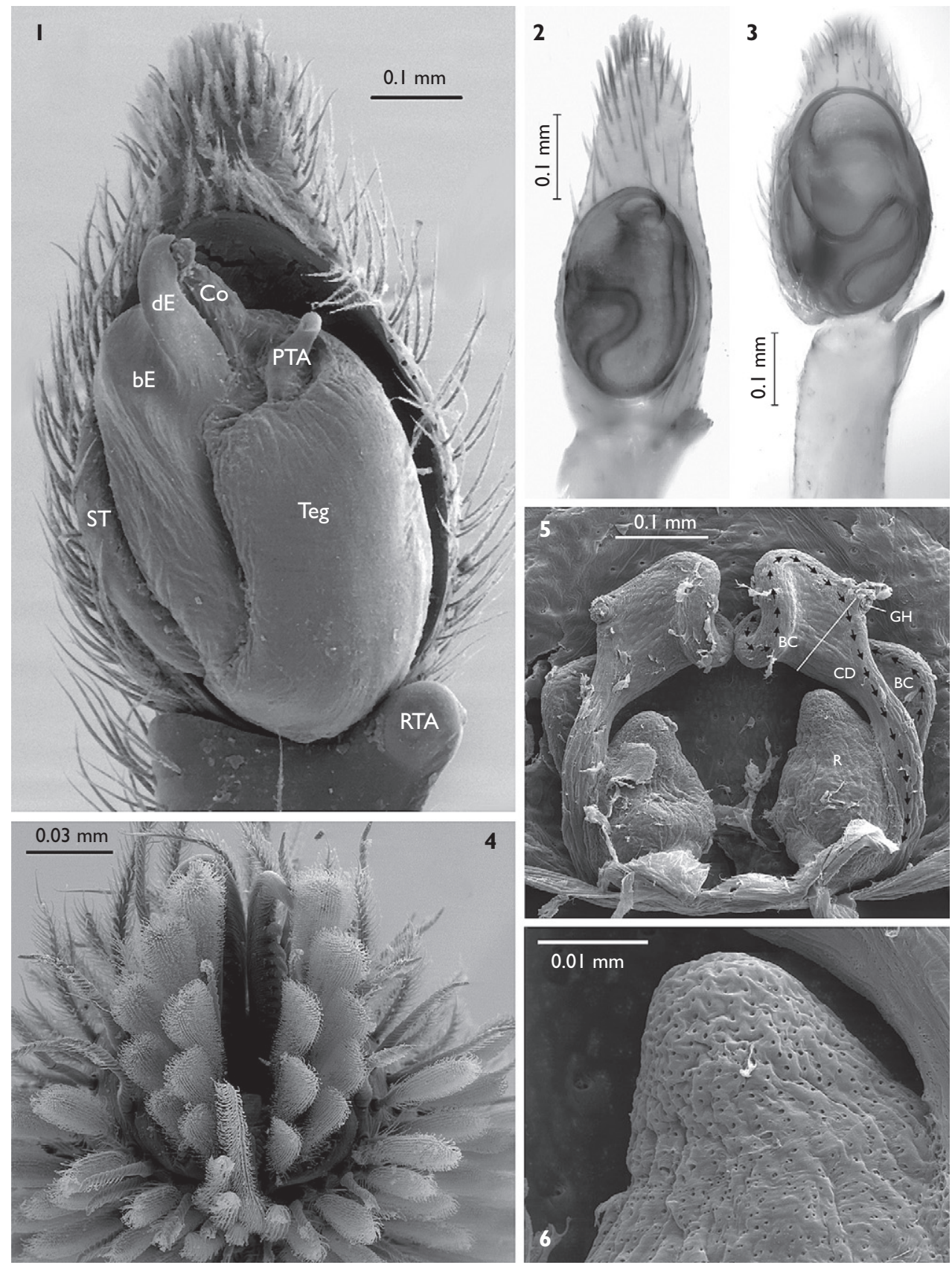

Figures I-6. I, 4 Halodromus patellaris from Monastir 2 Ebo pepinensis from Utah Lake 3 Titanebo albocaudatus from Abilene 5-6 Titanebo andreaannae from Tucson I-3 Left male palp, ventral view 4 Tarsal claws and scopulae 5 Epigyne, dorsal view, showing schematic course of the internal ducts (broken black line) and the demarcation between bursa copulatrix and copulatory ducts (white line) 6 Details of receptacula, showing numerous pores in the torus region. 
$\begin{array}{ll}\text { CM } & \text { Coll. Christoph Muster, Putbus } \\ \text { CTh } & \text { Coll. Konrad Thaler \& Barbara Knoflach, Innsbruck } \\ \text { CJW } & \text { Coll. Jörg Wunderlich, Hirschberg-Leutershausen } \\ \text { MNHN } & \text { Muséum National d'Histoire Naturelle, Paris } \\ \text { MHNG } & \text { Muséum d'Histoire Naturelle, Genève } \\ \text { NHMB } & \text { Naturhistorisches Museum, Basel } \\ \text { SMF } & \text { Forschungsinstitut Senckenberg, Frankfurt a. M. } \\ \text { SZMN } & \text { Siberian Zoological Museum, Novosibirsk } \\ \text { TAU } & \text { Tel Aviv University, Tel Aviv } \\ \text { ZMUM } & \text { Zoological Museum of the Moscow State University, Moscow }\end{array}$

Specimens were examined and measured using a Zeiss STEMI 2000 stereoscopic microscope with a micrometer eyepiece. All measurements are in millimetres. For leg measurements, the variation is given for the entire leg followed by average values for the leg segments femur, patella, tibia, metatarsus and tarsus in squared brackets. The following morphometric indices turned out to be most useful for delineation of the Ebo-like genera: (i) the Leg II length index, which is the length of femur II divided by length of femur I, (ii) the AME size index, which is the diameter of AME divided by the width of the cephalothorax, (iii) the PME interdistance index, which is the distance between the PME divided by the distance PME-PLE (Schick 1965: 8), and (iv) the clypeus height index, which is the height of the clypeus divided by the width of the cephalothorax. For leg spination, the system of Ono (1988) was adopted. As the most distal pair of ventral spines is often shifted dorsally to a rather lateral position, this distal pair was ascribed to the ventral pairs of spines up to a lateral shift of $90^{\circ}$.

Male and female genitalia were dissected and studied as temporary mounts in Hoyer's solution (Kraus 1984) under a Nikon Eclipse E600 microscope with a drawing tube at the MNHN. Montage images were taken at the Zoological institute of the University of Greifswald with a Leica DFC 320 digital camera operating on a Leica Stereomicroscope MZ125. Images taken at different focal planes were assembled with the Helicon Focus Pro software (Helicon Soft Limited). SEM images were taken by the team of Peter Michalik (University of Greifswald) using the following protocol: specimens were dehydrated in graded ethanols, dried in a BAL-TEC CPD 030 critical point dryer using amylacetate as the intermedium, coated with gold-palladium in a Quorum Technologies SC7620 sputtering device and examined in a Leo DSM 940A scanning electron microscope.

Terminology of the genital organs largely follows the recent studies by Muster et al. (2007) and Szita and Logunov (2008). Glandular heads are treated as synonymous with spermathecal organs. As the use of the term "Bursa copulatrix" has been controversial in the past, I here applied a rigid definition as proposed by Muster (2009): the "bursa copulatrix" is a canal or three-dimensional region of the vulva that is passed by the embolus during copulation before it enters the receptacula and that is not connected with the duct leading to the glandular heads. If the intromittent canal is merged with the ducts of the glandular heads, this structure is called a "copulatory duct". In this meaning "bursa copulatrix" is synonymous with "insemination duct" as used by 
Szita and Logunov (2008). The white line in Fig. 5 demarcates the transition from bursa copulatrix to copulatory ducts according to this definition. The various parts of the cephalothorax were named according to Schick (1965: 9).

Abbreviations used in text and figures: AGP - anterior guide pockets; ALE - anterior lateral eyes; $\mathbf{A M E}$ - anterior median eyes; $\mathbf{B C}$ - bursa copulatrix; $\mathbf{b E}$ - basal embolus; CD - copulatory duct; CL - cephalothorax length; $\mathbf{C l y H ~ - ~ c l y p e u s ~ h e i g h t ; ~} \mathbf{C o}$ - conductor; CW - cephalothorax width; CyL - cymbium length; $\mathbf{C y W}$ - cymbium width; dE - distal embolus; EG - epigynal groove; ES - epigynal suture; FD - fertilisation duct; Fem - femur; GH - glandular head; MS - median septum; OL - opisthosoma length; OW - opisthosoma width; PatApo - patellar apophysis of male palp; PGP - posterior guide pockets; PFem - length of palpal femur; PLE - posterior lateral eyes; PME - posterior median eyes; PPat - length of palpal patella; PTA - philodromid tegular apophysis; PTib - length of palpal tibia; R - receptaculum; RTA - retrolateral tibial apophysis; SD - sperm duct loop; ST - subtegulum; Teg - tegulum; VTA - ventral tibial apophysis.

\section{Taxonomy}

\section{Key to genera of Ebo-like Philodromidae (VMA enlarged, leg II elongated)}

1 Tibiae and metatarsi of legs without pro- and retrolateral spines ........... Ebo

- $\quad$ Tibiae and metatarsi of legs with pro- and retrolateral spines..................... 2

2 Prosoma longer than wide (or at least as long as wide), leg II moderately elongated, at most 1.4 times longer than leg I.

Philodromus histrio group (Rhysodromus)

- $\quad$ Prosoma wider than long (or at least as wide as long, Figs 11-16), leg II strongly elongated, more than 1.4 times longer than leg I ..................... 3

3 Leg IV longer or as long as leg I, male palp without patellar apophysis and PTA, embolus curved, with filiform tip pointing to palpal tibia (Fig. 3), epigyne without sclerotised guide pockets Titanebo

- $\quad$ Leg IV shorter than leg I, male palp with patellar apophysis and PTA, embolus stout, its tip pointing to cymbium tip (Figs 1,21), epigyne with sclerotised guide pockets (Figs 27, 35)

Halodromus gen. $\mathbf{n}$.

\section{Genus Ebo Keyserling, 1884}

Ebo Keyserling, 1884: 678. - Simon 1895: 1063; Schick 1965: 84 (subgenus Ebo); Sauer and Platnick 1972: 36-37 (subgenus Ebo); Dondale and Redner 1978: 29-30 (ad part.).

Type species. Ebo latithorax Keyserling, 1884 by monotypy

Material examined. Ebo evansae Sauer \& Platnick, 1972: USA: Utah: 4ð̄, 4ㅇ, Salt Lake City, dry canyon, 40 $46^{\prime} \mathrm{N}, 111^{\circ} 50^{\prime} \mathrm{W}, 11$ March 1944, leg. W. Ivie (AMNH). 
Ebo latithorax: USA: Pennsylvania: $2{ }^{`}$, Rector, 40 $12^{\prime} \mathrm{N}, 7^{\circ} 14^{\prime} \mathrm{W}, 20$ June 1967 , leg. B. Vogel (AMNH). Ebo cf. latithorax: USA: Kansas: $10^{\circ}, 5$ ㅇ, Ellsworth, $38^{\circ} 34^{\prime} \mathrm{N}$, 98 14'W, 23 August 1935, leg. W. Ivie (AMNH). Ebo pepinensis Gertsch, 1933: USA: Utah: $30^{\wedge}, 3$, west side of Utah Lake, $40^{\circ} 16^{\prime} \mathrm{N}, 111^{\circ} 56^{\prime} \mathrm{W}, 11$ March 1934, leg. W. Ivie (AMNH).

Diagnosis. Philodromid spiders with enlarged AME (AME size index 0.067-0.08) and extremely elongated leg II (Leg II length index 1.5-2.2). Prosoma wider than long (Fig. 11). Clypeus low (Clypeus height index < 0.1, Fig. 7). Leg formula 2143. Spination of legs generally reduced with species-specific modifications (males of $E$. latithorax are completely spineless), tibiae and metatarsi always without pro- and retrolateral spines. Metatarsus III and IV ventral 2-2-2 (except E. latithorax). Patella of male palp without apophysis, tibia with indistinct VTA (sometimes completely reduced) and small, weakly sclerotized RTA. Embolus curved, its tip flexible, pointing to retrolateral side (Fig. 2). Tegulum without apophysis. Conductor a retrolateral shallow groove. Epigyne weakly sclerotized, without atrium or grooves, epigynal suture entirely shifted to epigastric furrow. Glandular heads separated from receptacula, connected by thin ducts.

Remarks. The Nearctic Ebo species were thoroughly revised by Schick (1965) and Sauer and Platnick (1972). In both these studies Titanebo described by Gertsch (1933) was regarded a subgenus of Ebo. All Nearctic species indeed share a number of characters, e.g. the lack of PTA, the curved embolus with a flexible tip and the constitution of the conductor. However, the leg spination pattern is strikingly different, with Titanebo resembling Rhysodromus (the Philodromus histrio group) and Halodromus gen. n. Ebo and Titanebo are also different in the structure of the female genitalia and in some morphometric indices (Table 1). In none of the phylogenetic analyses performed by Muster (2009) did Titanebo emerge as sister to Ebo. In conclusion, Titanebo clearly deserves generic re-establishment.

Table I. Morphometric indices in Ebo-like philodromid genera. Leg II length index = length femur II/femur I; AME size index = diameter AME/CW; PME interdistance index = PME-PME/PME-PLE; clypeus height index $=\mathrm{ClyH} / \mathrm{CW}$.

\begin{tabular}{lcccc}
\hline & Ebo & Titanebo & Halodromus & $\begin{array}{c}\text { Philodromus } \\
\text { bistrio group }\end{array}$ \\
\hline males & & & & \\
leg II length index & $1.6-2.1$ & $1.5-1.7$ & $1.4-1.5$ & $1.1-1.4$ \\
AME size index & $0.071-0.077$ & $0.054-0.076$ & $0.063-0.084$ & $0.035-0.058$ \\
PME interdistance index & $1.88-2.11$ & $1.80-2.07$ & $1.56-2.00$ & $1.63-3.00$ \\
clypeus height index & $0.08-0.10$ & $0.14-0.18$ & $0.12-0.21$ & $0.16-0.18$ \\
females & & & & \\
leg II length index & $1.5-2.2$ & $1.4-1.7$ & $1.3-1.6$ & $1.1-1.3$ \\
AME size index & $0.067-0.068$ & $0.060-0.067$ & $0.061-0.087$ & $0.038-0.053$ \\
PME interdistance index & $1.88-2.26$ & $1.69-1.87$ & $1.35-2.09$ & $1.46-2.33$ \\
clypeus height index & $0.09-0.10$ & $0.15-0.18$ & $0.11-0.18$ & $0.16-0.18$ \\
\hline
\end{tabular}


Composition and distribution. The centre of diversity is undoubtly North America. Sauer and Platnick (1972) included seven Nearctic species in the subgenus Ebo: E. contrastus Sauer \& Platnick, 1972, E. evansae Sauer \& Platnick, 1972, E. iviei Sauer \& Platnick, 1972, E. lathithorax Keyserling, 1884, E. merkeli Schick, 1965, E. pepinensis Gertsch, 1933, and E. punctatus Sauer \& Platnick, 1972. Two further species were added by Platnick (1972) and Cokendolpher (1978), E. bucklei Platnick, 1972, and E. redneri Cokendolpher, 1978. Old World species described in Ebo are either transferred to Halodromus gen. n. or Philodromus, or they are regarded together with three Neotropical species as incertae sedis.
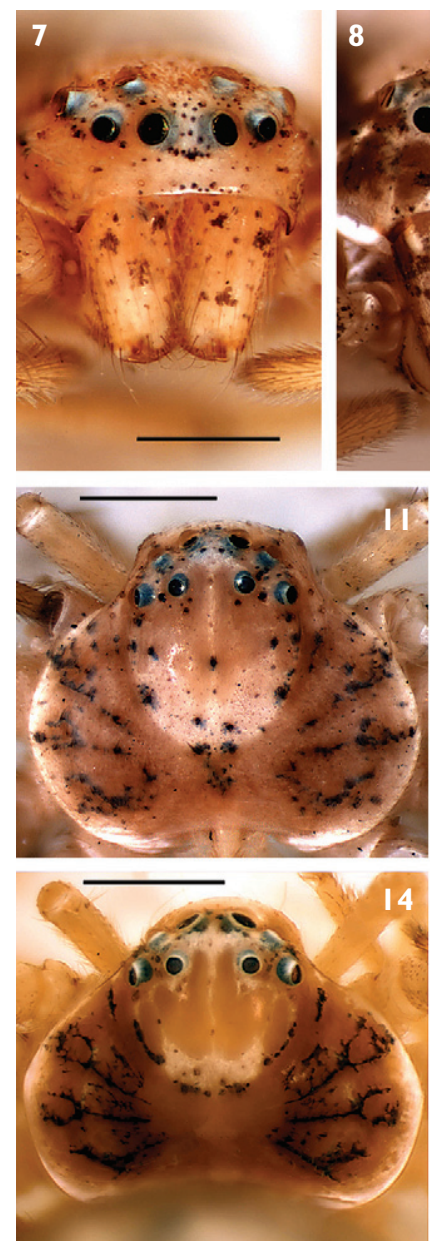
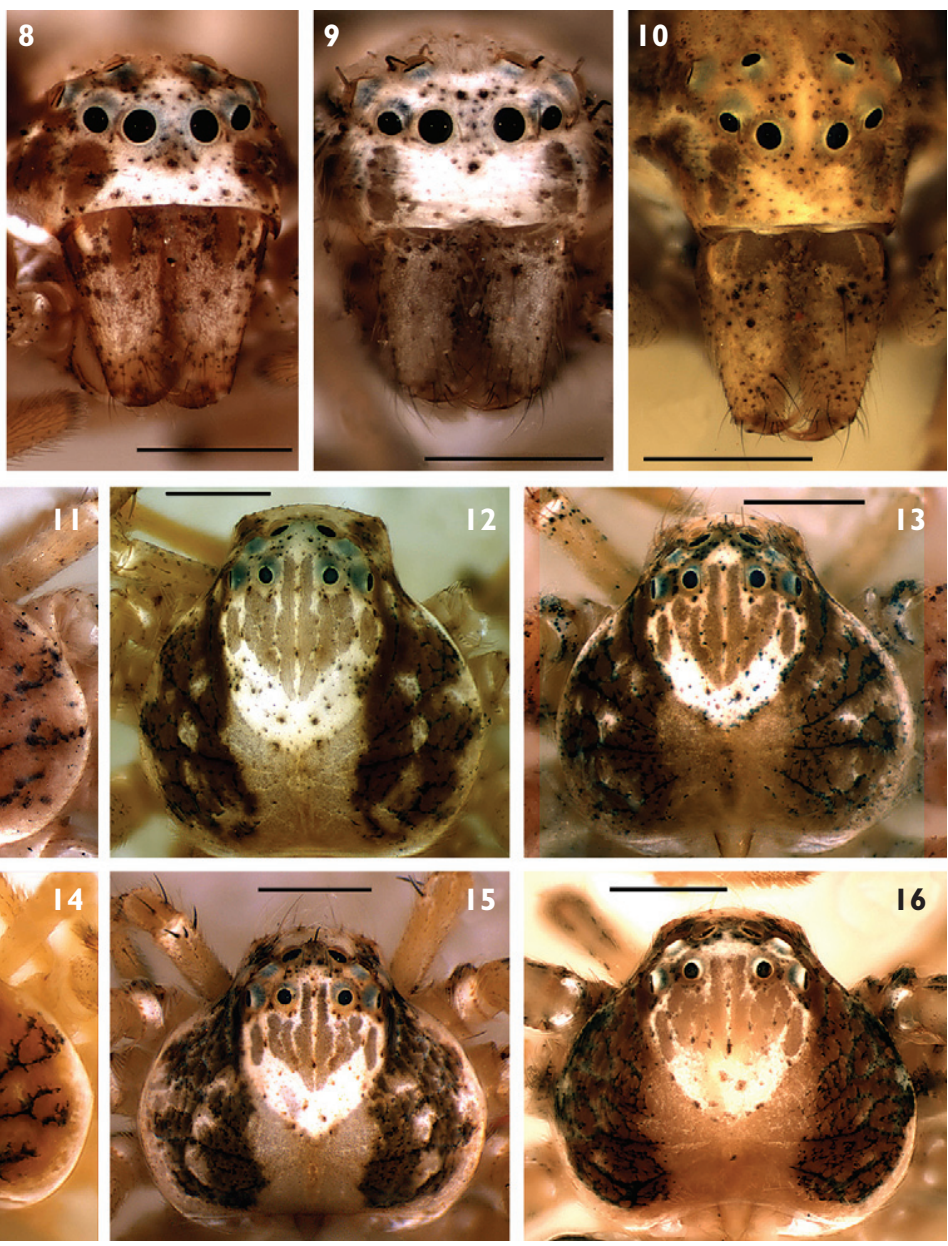

Figures 7-16. 7, I I Ebo pepinensis from Utah Lake 8, 12 Titanebo parabolis from Utah 9, I5 Halodromus patellaris, from Monastir 10 Philodromus lepidus from Kebili, Tunisia $\mathbf{1} 3$ Halodromus patellidens from Kuwait 14 Halodromus barbarae sp. n. from Cartagena $\mathbf{6} 6$ Halodromus gershomi sp. n. from Massawa 7-10 Female clypeus and chelicerae, frontal view II-I6 Female cephalothorax, dorsal view. Scale lines = $0.5 \mathrm{~mm}$. 


\section{Genus Titanebo Gertsch, 1933}

Titanebo Gertsch, 1933: 10-11.

Ebo (Titanebo) Gertsch, 1933 - Schick 1965: 73-75 (relegated to subgenus level);

Sauer and Platnick 1972: 36.

Ebo Keyserling, 1884 - Dondale and Redner 1978: 29-30 (ad part.).

Type species. Titanebo macyi Gertsch, 1933 by original designation.

Material examined. Titanebo albocaudatus (Schick, 1965): USA: Texas: $1{ }^{\top}$, Abilene, $32^{\circ} 27^{\prime} \mathrm{N}$, $99^{\circ} 46^{\prime} \mathrm{W}$, June 1962, leg. K. W. Haller (AMNH); 1 \% , Quemado, $28^{\circ} 56^{\prime} \mathrm{N}$, $100^{\circ} 37^{\prime} \mathrm{W}$, leg. W. J. Gertsch et al. (AMNH). MEXICO: Coahuila: $10^{\top}$, La Gloria, $26^{\circ}$ $41^{\prime} \mathrm{N}, 101^{\circ} 22^{\prime} \mathrm{W}, 24$ August 1947, leg. W. J. Gertsch (AMNH). Titanebo andreaannae (Schick, 1965): USA: Arizona: $10^{\lambda}, 39$, Tucson, $32^{\circ} 15^{\prime} \mathrm{N}, 110^{\circ} 57^{\prime} \mathrm{W}$, leg. O. Bryant (AMNH). Titanebo mexicanus (Banks, 1898): USA: Arizona: $1 \hat{\jmath}$, 1 , Welton-Mohawk, $32^{\circ} 44^{\prime} \mathrm{N}, 113^{\circ} 46^{\prime} \mathrm{W}, 9$ December 1955, leg. V. Roth (AMNH). MEXICO: Chihuahua: $10^{\uparrow}, 4$, 2 juv. Samalayuca Dunes, $31^{\circ} 21^{\prime} \mathrm{N}, 106^{\circ} 28^{\prime} \mathrm{W}, 25$ June 1947, leg. W. J. Gertsch (AMNH). Titanebo parabolis (Schick, 1965): USA: Utah: 40 ${ }^{\lambda}$, 69, American Fork Canyon, $40^{\circ} 25^{\prime} \mathrm{N}, 111^{\circ} 45^{\prime} \mathrm{W}, 12$ May 1934, leg. W. Ivie (AMNH).

Diagnosis. Philodromid spiders with moderately enlarged AME (AME size index 0.054-0.076) and strongly elongated leg II (Leg II length index 1.4-1.7). Prosoma as wide as long (Fig. 12). Clypeus of intermediate height (Clypeus height index 0.14-0.18, Fig. 8). Leg formula 2413 (occasionally 2143, but then leg IV almost as long as leg I). Spination of leg I: femur dorsal 0-1-1, prolateral 0-1-1-[01]; tibia ventral 2-2-0, pro- and retrolateral [01]-1-1, dorsal 0-0-1; metatarsus ventral 2-2-0, pro- and retrolateral [01]-1-1, dorsal 0 -[01]. Metatarsus III and IV ventral 2-2-2. Patella of male palp without apophysis, tibia with two well developed apophyses, VTA a colourless lobe in close contact to the heavily sclerotized RTA, tip of RTA pointed and dentated. Embolus curved, its elongated, filiform tip pointing to RTA (Fig. 3). Tegulum without apophysis. Conductor in form of elongate retrolateral groove. Epigyne weakly sclerotized, without atrium or grooves. Vulva (Fig. 5) lateral and anterior of receptacula with long, sclerotised introductory tubes (= bursa copulatrix) on which the glandular heads (=spermathecal organs) sit, thus becoming copulatory ducts in the distal part. Receptacula with glandular mounds (=torus, Fig. 6).

Remarks. Titanebo is herewith re-elevated to full genus status; for a justification see remarks on Ebo. Titanebo species from North America were thoroughly revised by Schick (1965) and Sauer and Platnick (1972).

Composition and distribution. The genus comprises 14 Nearctic species: Titanebo albocaudatus (Schick, 1965), T. andreaannae (Schick, 1965), T. californicus Gertsch, 1933, T. cantralli (Sauer \& Platnick, 1972), T. cresotis (Schick, 1965), T. dispar (Schick, 1965), T. dondalei (Sauer, 1968), T. macyi Gertsch, 1933, T. magnificus Chamberlin \& Ivie, 1942, T. mexicanus (Banks, 1898), T. oblongus (Simon, 1895), T. parabolis (Schick, 1965), T. redneri (Cokendolpher, 1978), and T. texanus Gertsch, 1933. The primary centre of distribution is presumably the desert and shrub region of the southwestern Nearctic (Schick 1965). 


\section{Genus Philodromus Walckenaer, 1826 ad part. (the Philodromus histrio species group)}

Rhysodromus Schick, 1965: 67.

Philodromus histrio species group - Dondale and Redner 1975: 370, 372; Szita and Logunov 2008: 25-27.

Type species of Rhysodromus: Thomisus histrio Latreille, 1819.

Diagnosis. Philodromus spiders with some Ebo-like characters: AME larger than other eyes (AME size index 0.035-0.06), leg II moderately elongated (Leg II length index 1.1-1.4). Prosoma longer than wide (or at least as wide as long). Clypeus high (Clypeus height index > 0.16, Fig. 10). Spination of legs similar to Halodromus and Titanebo, but more variable. Metatarsus III and IV ventral 2-2-2 (if always?). Patella of male palp usually without apophysis, in subgenus Locupletes Schick, 1965 with small apical apophysis (< 1/4 length of patella), palpal tibia with 0-2 apophyses. Embolus stout, its tip pointing to cymbium tip. PTA present or absent. Conductor a membraneous outgrowth at anterior margin of tegulum. Female genitalia not clearly distinguishable from Halodromus.

Remarks. The eastern-Palaearctic species of the Philodromus histrio group were recently reviewed by Szita and Logunov (2008), but delineation of the taxon remained vague and no evidence for monophyly of the included species was provided. The histrio group in its current limits is most likely an artificial assemblage of superficially similar species. A recent cladistic analysis within Philodromidae (Muster 2009) has shown that histrio and related species are more closely related to the Thanatini (Thanatus and Tibellus) than to other Philodromus species groups. Thus, Rhysodromus clearly deserves re-elevation to genus rank, but the urgently required revision of the histrio group from a phylogenetic perspective is beyond the scope of this study.

Composition and distribution. Szita and Logunov (2008) include 16 species from the eastern Palearctic in the Philodromus histrio group. In the Nearctic the taxon is represented by three polytypic species (Schick 1965; Dondale and Redner 1975). The group also occurs in the Mediterranean and in (northern) Africa, but species from this region still await a proper revision. Philodromus halophilus (Levy, 1977) comb. n. is transferred from Ebo to this group. The male lacks a patellar apophysis and the morphometric indices fall well within the range of the histrio group.

Genus Halodromus gen. n.

urn:lsid:zoobank.org:act:17BBE7AC-82E4-4E04-BF23-BA84DE086EE4

Ebo Keyserling, 1884 - Levy 1977: 207-208 (ad part.); Wunderlich 1987: 261.

Type species. Ebo patellidens Levy, 1977

Etymology. The name Halodromus refers to the habit of hiding in salt tolerant dwarf shrubs and the relationship to some Philodromus (Rhysodromus) species. Gender masculine. 
Diagnosis. Philodromid spiders with enlarged AME (AME size index 0.0630.087 ) and strongly elongated leg II (Leg II length index 1.3-1.6). Prosoma wider than long (Figs 13-16). Clypeus of intermediate height (Clypeus height index 0.11-0.21, Fig. 9). Leg formula 2143. Spination of leg I: femur dorsal 0-1-1, prolateral 0-1-1; tibia ventral 2-2-0, pro- and retrolateral 0-1-1, dorsal 0-0-1; metatarsus ventral 2-20 , pro- and retrolateral 1-1-1. Metatarsus IV ventral 2-2-2. Patella of male palp with long apophysis (at least half the length of patella), tibia with rounded RTA (Figs 17, 21, 25, 29, 33). Embolus stout, its tip pointing to cymbium tip (Fig. 1). PTA present. Conductor a narrow membrane accompanying distal embolus (Fig. 1). Epigyne with pair of both anterior and posterior guide pockets (Figs 19, 23, 27, 31, 35). Glandular heads without ducts, sitting at main body of receptacula.

Description. Somatic features. Small to moderately sized philodromid spiders, total length $(\delta / O, \mathrm{n}=14 / 25)$ 2.0-3.7 / 2.6-5.1, cephalothorax width 0.95-1.75/1.15-1.85. Cephalothorax (Figs 13-16) slightly wider than long $(\mathrm{CW} / \mathrm{CL}=1.03-1.32)$, dorsal shield brownish with light median band that extends to posterior declivity, metadiscus a whitish V-sign, mesodiscus with conspicuous pattern, allatum usually with reticulating dark lines, posterior edges whitish with pubescence. Eyes in two slightly recurved rows, the second row almost straight, AME distinctly larger than other eyes (AME/ PME 1.25-1.8), AME size index (AME/CW) 0.063-0.087, AME closer to ALE than to each other, PME interdistance index (PME-PME/PME-PLE) 1.35-2.09, PME almost equidistant to PLE and ALE, lateral eyes larger than medians. Clypeus 1.5 to 3 times as high as diameter of AME (Fig. 9), clypeus height index (ClyH/CW) 0.110.21 , often with light patch. Cheliceral furrow without promarginal teeth. Leg formula 2143, leg II strongly elongated, Fem II 1.4-1.55 times longer than Fem I (length femur I 1.15-2.2 / 1.25-2.25, length fem II 2.25-3.25 / 1.85-3.1). Spination of leg I: femur dorsal 0-1-1, prolateral 0-1-1; tibia ventral 2-2-0, pro- and retrolateral 0-1-1, dorsal 0-0-1; metatarsus ventral 2-2-0, pro- and retrolateral 1-1-1. Spination of other legs similar, only metatarsus IV ventral 2-2-2. Tarsi and distal half of metatarsi densely covered with scopulae (Fig. 4). Legs yellowish to orange brown, usually mottled and with twofold annulations at femora, threefold annulations at tibiae and weak annulation at metatarsi. Opisthosoma oval, widest near middle, sides smoothly rounded, posteriorly tapering. Dorsum grey with conspicuous black cardiac mark, flanks often darkish, in posterior half with four to five chevrons.

Pedipalp (Figs 1, 17-18, 21-22, 25-26, 29-30, 33-34). Patella with long retrolateral apophysis that is 0.4 to 1.2 times as long as tibia. Tibia with relatively short, broadly rounded RTA, VTA absent, tibia approximately half as long as cymbium. Cymbium drop-like, cymbial tip relatively short, covered with chemosensitive hairs. Cymbium length $(\mathrm{CyL})$ 0.440.74, width (CyW) 0.2-0.44, ratio CyL/cephalothorax width 0.36-0.46. Subtegulum visible in ventral view. Tegulum with large, hooked PTA in retrolateral-distal position. Sperm duct opening between 7 and 9 o'clock position. Conductor a narrow, membranous distal outgrowth of tegulum, partially hidden behind embolus. Embolus at prolateral side of tegulum, divided in basal and distal embolus. Basal embolus widely merged with tegulum, distally often bulged. Distal embolus a stiff, thorn-like structure, pointing to cymbial tip. 
Epigyne-vulva (Figs 19-20, 23-24, 27-28, 31-32, 35-36). Median septum divides the atrium in two epigynal grooves (e.g. Fig. 27), or epigynal sutures may be covered by lateral plates, leaving no atrium visible (Fig. 35). Epigyne with two pairs of lateral guide pockets, the posterior guide pockets may be indistinct, anterior guide pockets are heavily sclerotised. Anterior guide pockets may serve for fixation of palpal patella during copulation, the intromittant orifice is presumably situated at the anterior end of the epigynal suture. Receptacula of variable shape, situated near the epigastric furrow (Fig. 32) or shifted anteriorly (Figs 24, 36), touching each other (Figs 20, 36) or well separated (Fig. 32). Glandular heads in anterior position at receptacula, ducts very short or absent, independent from intromittent canal. No glandular mounds appreciable at walls of receptacula. Fertilisation ducts at posterior end of receptacula.

Composition and distribution. Five species from Northern Africa (including the Canary and Cape Verde islands) and the Middle East (one presumably reaching the Iberian Peninsula) are included in the new genus. Two of them were hitherto placed in the genus $E b o$, three species are newly described. While all species are present in the region around the Red Sea, three are rather widespread in the area outlined above (Fig. 37).

\section{Key to the Halodromus species}

$1 \quad$ Males n...

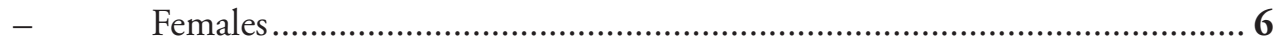

2 Patellar apophysis longer than tibia of male palp, PTA laminate, projecting beyond retrolateral margin of tibia (Figs 33-34) .....................H. patellidens

- $\quad$ Patellar apophysis not longer than $3 / 4$ the length of tibia of male palp, PTA hooked, not projecting beyond retrolateral margin of tibia (e.g. Fig. 17) .... 3

3 Embolus with distinct prolateral bulge at basis of distal embolus (Figs 21, 25, 29), RTA a wide, rounded projection........................................................ 4

- $\quad$ Embolus without distinct prolateral bulge at basis of distal embolus, RTA reduced to a small hump (Figs 17-18) ..... H. barbarae sp. $\mathrm{n}$.

4 Distal embolus stout, curved to retrolateral side, PTA narrow (Figs 1, 29-30) H. patellaris

Distal embolus a thin spur, PTA large (Figs 21, 25) 5 Patellar apophysis with distinct bulge at base of ventral margin (Figs 21-22)

H. deltshevi sp. $\mathrm{n}$.

Patellar apophysis at ventral margin only with inconspicuous groove (Figs 25-26) H. gershomi sp. n.

Median septum with parallel margins (Figs 19, 31)

Epigyne longer than wide, glandular heads in lateral-distal position at receptacula (Figs 19-20)

H. barbarae sp. $\mathrm{n}$.

- $\quad$ Epigyne wider than long, glandular heads in mid-distal position at receptacula (Figs 31-32) 
8 Epigyne without grooves, anterior guide pockets covered by receptacula in dorsal view (Figs 35-36)

H. patellidens

- $\quad$ Epigyne with extended grooves, anterior guide pockets visible in dorsal view (Figs 23, 27) 9

9 Epigyne longer than wide, epigynal sutures sigmoid (Fig. 23)

H. deltshevi sp. $\mathrm{n}$.

- $\quad$ Epigyne wider than long, epigynal sutures straight (Fig. 27)

H. gershomi sp. n.

\section{Halodromus barbarae sp. $\mathbf{n}$.}

urn:lsid:zoobank.org:act:994C72B5-39E7-4520-8902-31614C7126B5

Figs 14, 17-20

Ebo spec. (?patellaris Wunderlich, 1987) - Schmidt and Krause 1996: 267-268, fig. 7 (misidentification).

Etymology. The species is named after Dr Barbara Thaler-Knoflach in recognition of her merits in the exploration of theridiid spiders of the Mediterranean basin and beyond. Noun in genitive case.

Material examined. Holotype. Male. SPAIN: Murcia: Cartagena, $37^{\circ} 36^{\prime} \mathrm{N}, 0^{\circ}$ $59^{\prime} \mathrm{W}$, leg. E. Simon, specimen in ethanol with left palp dissected, with hand-written labels as follows "13388 Cartagena!" "Halodromus barbarae Muster Holotype" (MNHN ES 13388). Paratypes. EGYPT: Aswan: 1 , Assuan synanthropic, $24^{\circ} 4^{\prime} \mathrm{N}$, $32^{\circ} 55^{\prime} \mathrm{E}, 22$ June 1975, leg. Kübelböck (MNHG). ISRAEL: Southern District: 1ㅇ, Arava Valley, 'Iddan, $30^{\circ} 47^{\prime} \mathrm{N}, 35^{\circ} 17^{\prime} \mathrm{E}, 2$ September 2008, D-Vac leg. V. Hochmann (TAU). SAUDI ARABIA: Eastern Province: $1{ }^{\top}$, Al-Khobar, $26^{\circ} 17^{\prime} \mathrm{N}, 50^{\circ} 12^{\prime} \mathrm{E}, 12$ January 1983, leg. E. Heiss (MNHG). SPAIN: Murcia: 3 , 2 juv., Cartagena, $37^{\circ}$ 36’N, $0^{\circ} 59^{\prime} W$, leg. E. Simon (MNHN ES 13388).

Diagnosis. Males are characterized by the shape of the embolus ("foxtailed") and by the RTA reduced to a small bulge (Fig. 17). Females show a unique shape of the receptacula (Fig. 20).

Description. Measurements. Male $(\mathrm{n}=2)$ : total length 2.05-3.0, CL 0.9-1.39, CW 0.95-1.45, ClyH 0.11-0.21, OL 1.25-1.9, OW 1.0-1.4. Leg I 3.77-6.2 [1.45, $0.55,1.25,1.1,0.64]$, FemII 2.65. Eye sizes and interdistances: AME 0.08-0.11, PME 0.04-0.06, AME-AME 0.1-0.14, AME-ALE 0.05, PME-PME 0.16-0.21, PMEPLE 0.09-0.12, ALE-PME 0.1-0.13. Pedipalp: PFem 0.36-0.56, PPat 0.15-0.24, PatApo 0.8-0.13, PTib 0.18-0,26, CyL 0.44-0.58, CyW 0.2-0.3. AME size index: 0.073-0.084. PME interdistance index: 1.72-1.76. Clypeus height index: 0.12-0.15. Leg II length index: 1.51.

Female $(\mathrm{n}=5)$ : total length $3.6(2.6-5.1)$, CL $1.2(1.05-1.35)$, CW $1.36(1.15-$ 1.55), ClyH 0.18 (0.16-0.22), OL 2.55 (1.8-3.2), OW 2.07 (1.45-2.7). Leg I 5.26 (4.18-6.15) [1.58, 0.58, 1.31, 1.08, 0.71], FemII 2.29 (1.85-2.7). Eye sizes and inter- 
distances: AME 0.1, PME 0.064, AME-AME 0.1, AME-ALE 0.046, PME-PME 0.21, PME-PML 0.12, ALE-PME 0.13. AME size index: 0.075 (0.061-0.087). PME interdistance index: 1.78 (1.59-2.09). Clypeus height index: 0.14 (0.11-0.15). LegII length index: 1.47 (1.46-1.48).

Colour. Pale species. Dorsal shield of prosoma (Fig. 14) light brown with yellowish median band that extends to posterior margin, posterior edges with whitish pubescence, allatum with radiating, furcated stripes of dark spots, whitish patches along longitudinal allatal stripes, metadiscus a central whitish W-sign, mesodiscus with inconspicuous pattern. Clypeus whitish, chelicerae uniformly beige. Sternum uniformly whitish with long pubescence. Legs yellowish-brown, mottled (particularly at prolateral-ventral side of femora), faint annulations distal at femora and basal and distal at tibia. Opisthosoma whitish grey with lanceolate cardiac mark, some dark patches and four to six chevrons in posterior half. Venter whitish grey.

Pedipalp (Figs 17-18). Patella with shortest apophysis among all known congeners, barely half as long as tibia. Tibia with RTA reduced to a low bulge. Cymbial tip less than one third of CyL. Cymbium length (CyL) 0.44-0.58, width (CyW) 0.2-0.3,
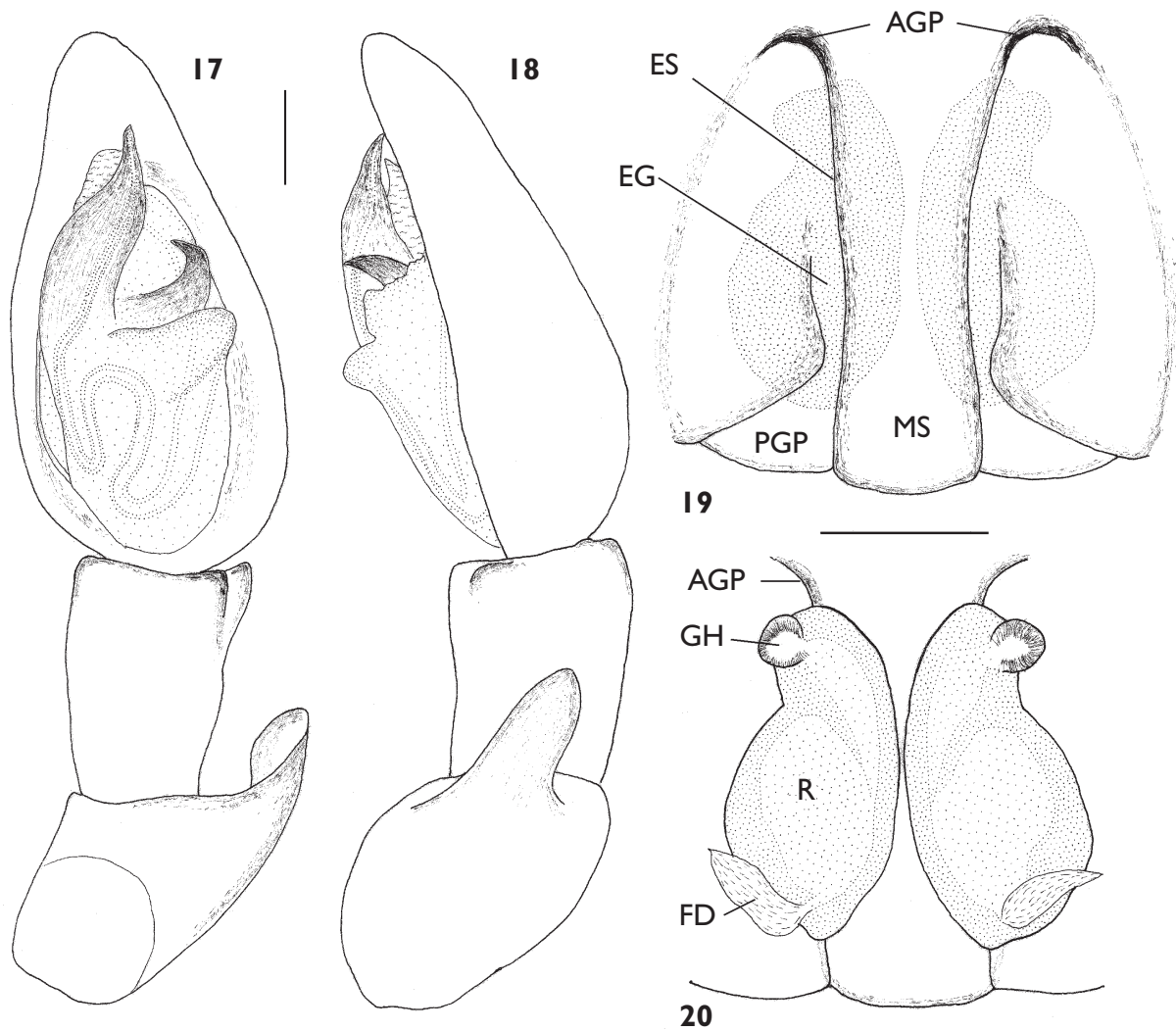

Figures 17-20. Halodromus barbarae sp. n. from Cartagena. I7- 18 Left male palp (I 7 ventral, 18 retrolateral) 19 Epigyne, ventral 20 Vulva, dorsal. Scale line $=0.1 \mathrm{~mm}$. 
ratio $\mathrm{CyL} /$ cephalothorax width $0.40-0.46$. Subtegulum visible in ventral view. Anterior border of tegulum bulged, PTA situated near this bulge, hooked, tip pointing ventrally. Sperm duct symmetric, opening in 7:30 o'clock position. Conductor largely hidden behind embolus, in ventral view protruding at prolateral side of embolus. Embolus not clearly divided in basal and distal part, foxtail-shaped, embolus tip straight, projecting beyond anterior border of bulb, pointing to cymbial tip.

Epigyne-vulva (Figs 19-20). Median septum with almost parallel margins, more than three times as long as wide, stretched grooves at both sides of median septum. Posterior guide pockets wide at epigastric furrow, anterior guide pockets small, moderately sclerotized. Receptacula kidney-shaped, in close contact. Glandular heads in lateral-distal position.

Remarks, distribution and habitat. Specimens from the Middle East are considerably smaller than those from Cartagena. However, there are no differences in the structure of the male and female genitalia, consequently there is no reason to doubt their conspecifity. The occurrence on the Iberian Peninsula needs to be confirmed, since the original labels of the type series from the Simon collection contained no other information than "13388 Cartagena!". This locality is somehow suspect because it is the single record of the genus from Europe. Given the wide range of $H$. patellaris and $H$. patellidens, this distribution is not entirely implausible, but at the same time it can not be excluded that Simon referred to the ancient city of Carthage in Tunisia. The species may also occur on the eastern Canary Islands. Schmidt and Krause (1996) illustrated the epigynum of a female from El Jable, Fuerteventura (mounted epigynum lost, Schmidt and Krause 1996: 268) that they provisionally allocated to Ebo patellaris, but they referred to differences from the original description by Wunderlich (1987). This figure corresponds well to $H$. barbarae, while it certainly does not show $H$. patellaris. No details on habitat were available from any of the original labels accompanying the specimens.

\section{Halodromus deltshevi sp. $\mathrm{n}$.}

urn:lsid:zoobank.org:act:0D97C753-718E-4BAF-BFA7-818A10F20BB3

Figs 21-24

Etymology. The species name is dedicated to the Bulgarian arachnologist Dr Christo Deltshev on occasion of his $70^{\text {th }}$ anniversary. Noun in genitive case.

Material examined. Holotype. Male. YEMEN: 'Adan: Aden, $12^{\circ} 48^{\prime} \mathrm{N}, 45^{\circ} 02^{\prime} \mathrm{E}$, 1889, leg. E. Simon, specimen in ethanol with three legs missing, with hand-written labels as follows "19099 Aden!" "Halodromus deltshevi Muster Holotype" (MNHN

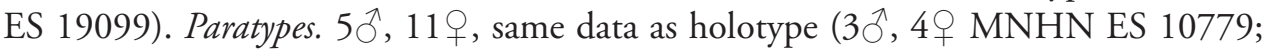
2ð, 7 MNHN ES 19099).

Diagnosis. Males are characterized by the prominent bulge at the base of the patellar apophysis (Figs 21-22), females are unique in the shape of the epigynal grooves (Fig. 23).

Description. Measurements. Male (Holotype): total length 3.25, CL 1.58, CW 1.65, ClyH 0.28, OL 1.9, OW 1.4. Leg I 7.4 [2.1, 0.75, 2.0, 1.6, 0.95], FemII 3.25. 
Eye sizes and interdistances: AME 0.12, PME 0.09, AME-AME 0.14, AME-ALE 0.055, PME-PME 0.27, PME-PLE 0.16, ALE-PME 0.14. Pedipalp: PFem 0.66, PPat 0.28, PatApo 0.28 PTib 0.32, CyL 0.66, CyW 0.34. AME size index: 0.073. PME interdistance index: 1.69. Clypeus height index: 0.17. Leg II length index: 1.55 .

Female $(\mathrm{n}=5)$ : total length $3.2(2.8-3.5)$, CL $1.34(1.25-1.4)$, CW 1.51 (1.4-1.6), ClyH 0.24 (0.23-0.26), OL 2.08 (1.7-2.2), OW 1.69 (1.4-1.9). Leg I 5.56 (5.4-5.75) $[1.69,0.6,1.43,1.13,0.71]$, FemII $2.42(2.3-2.65)$. Eye sizes and interdistances: AME 0.1, PME 0.07, AME-AME 0.11, AME-ALE 0.06, PME-PME 0.23, PME-PML 0.14, ALE-PME 0.13. AME size index: 0.068 (0.064-0.076). PME interdistance index: 1.65 (1.35-1.92). Clypeus height index: $0.16(0.15-0.17)$. LegII length index: $1.43(1.35-1.56)$.

Colour. Dorsal shield of prosoma brown with orange-brown median band that extends to posterior margin, posterior edges with whitish pubescence, allatal stripes discontinuous, metadiscus a central whitish V-sign, mesodiscus with conspicuous pattern (similar to Fig. 16). Clypeus brown with whitish patch, chelicerae light brown with black spots. Sternum whitish with dots and brown patches at the margin. Legs yellowish-brown, mottled and with double annulations at femora, single annulations at patel-
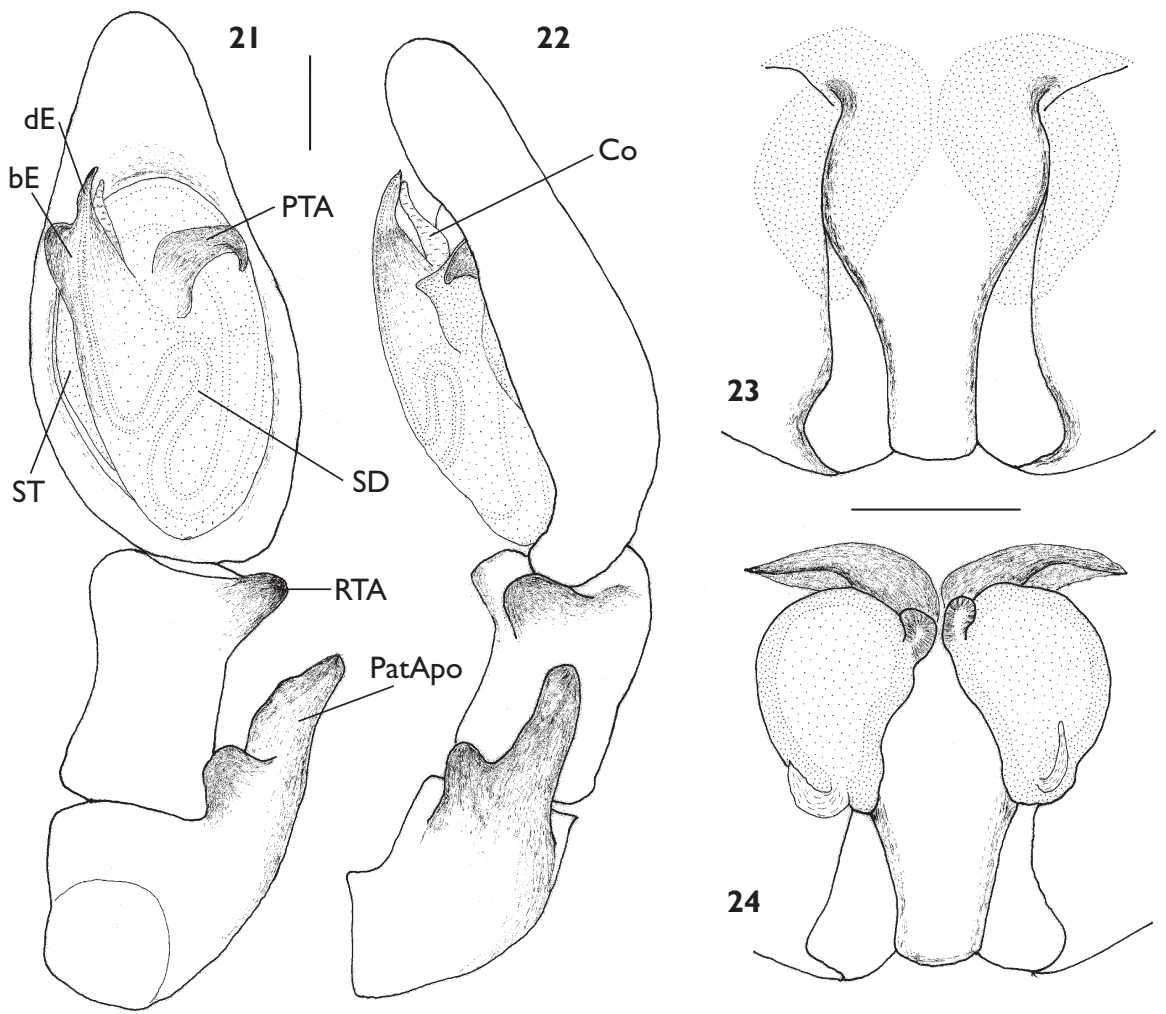

Figures 2I-24. Halodromus deltshevi sp. n. from Aden. 2I-22 Left male palp (2I ventral, 22 retrolateral) 23 Epigyne, ventral 24 Vulva, dorsal. Scale line $=0.1 \mathrm{~mm}$. 
lae, threefold annulations at tibiae and weak annulations at metatarsi. Opisthosoma densely covered with whitish pubescence, interspersed with dark setulae. Dorsum grey with lanceolate cardiac mark, two posterior dots are usually fused with the cardiac mark, flanks darkish. Venter whitish with grey patches and sometimes grey median stripe.

Pedipalp (Figs 21-22). Patella with bifid apophysis: a rounded bulge at ventral base and a long (three quarters the length of the tibia), blunt dorsal process. Tibia with short, rectangular processing RTA with rounded tip. Cymbial tip approximately one third of CyL. Cymbium length $(\mathrm{CyL})$ 0.66, width $(\mathrm{CyW})$ 0.34, ratio CyL/cephalothorax width 0.4 . Subtegulum visible in ventral view. Anterior border of tegulum indistinct, PTA originating in central position, hooked, tip pointing to RTA. Sperm duct symmetric, opening in 7:30 o'clock position. Conductor largely hidden behind embolus, in ventral view protruding at retrolateral side of embolus. Embolus at transition from basal to distal part with distinctive prolateral bulge that projects above prolateral margin of bulb, embolus tip a thin, slightly curved spur.

Epigyne-vulva (Figs 23-24). Epigyne longer than wide. Median septum narrowed posteriorly, epigynal sutures sigmoid. Epigynal grooves almost as wide as median plate at epigastric furrow. Posterior guide pockets relatively small, anterior guide pockets externally only moderately sclerotized, in dorsal view visible as voluminous pockets. Receptacula bagpipe-shaped, separated from epigastric furrow by approximately their diameter. Glandular heads in inner-distal position, almost touching one another.

Distribution and habitat. Only known from the type locality (Fig. 37), no information on habitat available.

\section{Halodromus gershomi sp. $\mathrm{n}$.}

urn:lsid:zoobank.org:act:7AA44C33-C217-4106-AC3A-B5206AC19FF5

Figs 16, 25-28

Etymology. The species is named in honour of Dr Gershom Levy, who described the first species of the genus from Israel and unfortunately passed away during preparation of this manuscript. Noun in genitive case.

Material examined. Holotype. Male. ERITREA: Semienawi Kayih Bahri [Northern Red Sea]: Massawa, $15^{\circ} 36^{\prime} \mathrm{N}, 39^{\circ} 27^{\prime} \mathrm{E}, 1889$, leg. F. Jousseaumme, specimen in ethanol with four legs missing, with hand-written labels as follows "11889 Massaua Philodromus" "Halodromus gershomi Muster Holotype" (MNHN ES 11889). Paratypes. $1{ }^{\lambda}, 12$,, 6 juv., same data as holotype (MNHN ES 11889).

Diagnosis. Males are distinguishable from similar species by the shape of patellar apophysis and PTA (Figs 25-26). The epigynum is wider than long with exceptionally wide posterior guide pockets (Fig. 27).

Description. Measurements. Male (Holotype): total length 3.3, CL 1.58, CW 1.65, ClyH 0.3, OL 2.15, OW 1.55. Leg I 7.55 [2.2, 0.9, 2.0, 1.5, 0.95], FemII 3.1. Eye sizes and interdistances: AME 0.1, PME 0.08, AME-AME 0.16, AME-ALE 0.088, PME-PME 0.29, PME-PLE 0.16, ALE-PME 0.15. Pedipalp: PFem 0.68, 
PPat 0.3, PatApo 0.2 PTib 0.3, CyL 0.6, CyW 0.3. AME size index: 0.063. PME interdistance index: 1.81. Clypeus height index: 0.18. LegII length index: 1.41.

Female $(\mathrm{n}=5)$ : total length $3.0(2.8-3.5)$, CL 1.28 (1.1-1.4), CW 1.46 (1.4-1.55), ClyH 0.23 (0.22-0.24), OL 1.97 (1.85-2.1), OW 1.6 (1.45-1.85). Leg I 5.09 (4.785.85) [1.54, 0.56, 1.28, 0.98, 0.73], FemII 2.18 (1.95-2.4). Eye sizes and interdistances: AME 0.1, PME 0.07, AME-AME 0.11, AME-ALE 0.06, PME-PME 0.24, PME-PML 0.14, ALE-PME 0.12. AME size index: 0.068 (0.061-0.076). PME interdistance index: 1.80 (1.66-2.0). Clypeus height index: 0.16 (0.15-0.18). Leg II length index: $1.42(1.3-1.5)$.

Colour. Dorsal shield of prosoma (Fig. 16) brown with wide orange-brown median band that extends to posterior margin, median band wider than the dark sides which show blackish venation, posterior edges with whitish pubescence, allatal stripes discontinuous, metadiscus a central whitish V-sign, mesodiscus with inconspicuous pattern. Clypeus brown with bi-humped beige area, chelicerae brown with black spots, distally more light. Sternum whitish with dots and brown patches at the margin. Legs yellowish-brown, mottled and with double annulations at femora, single annulations at patellae, threefold annulations at tibiae and weak annulations at metatarsi. Opisthosoma
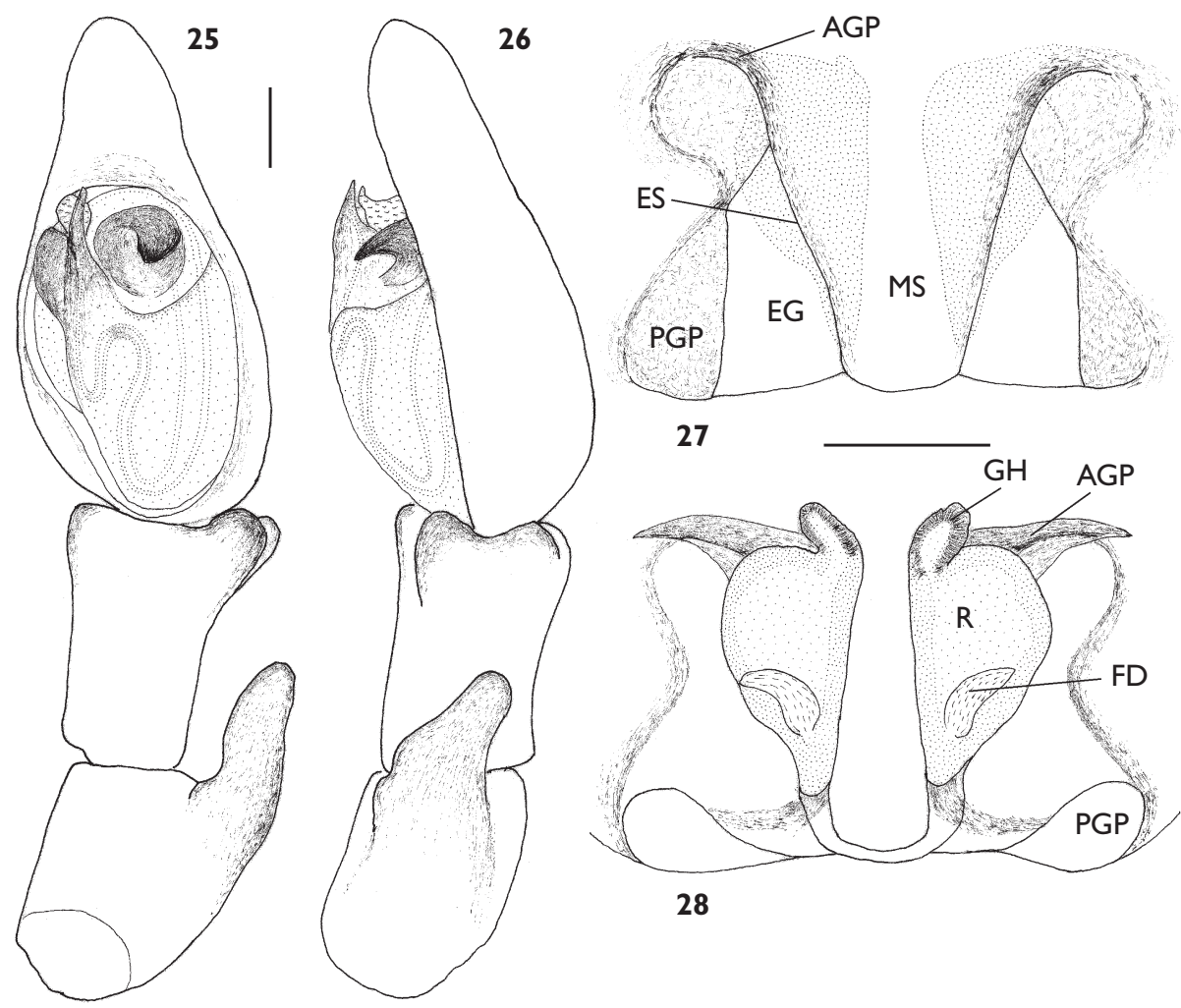

Figures 25-28. Halodromus gershomi sp. n. from Aden. 25-26 Left male palp (25 ventral, $\mathbf{2 6}$ retrolateral) 27 Epigyne, ventral 28 Vulva, dorsal. Scale line $=0.1 \mathrm{~mm}$. 
densely covered with whitish pubescence, interspersed with dark setulae. Dorsum grey with conspicuous black cardiac mark, followed by a separated black dot and grey chevrons posteriorly, flanks darkish. Venter whitish with a conspicuous, grey median stripe.

Pedipalp (Figs 25-26). Patellar apophysis less than two thirds the length of the tibia, with inconspicuous groove at ventral border, tip rounded, pointing to dorsal margin of tibia. Tibia with rectangular processing RTA with rounded tip which merges with a second, more dorsally situated bulge. Cymbial tip relatively long and narrow, approximately one third of CyL. Cymbium length $(\mathrm{CyL})$ 0.6, width $(\mathrm{CyW}) 0.3$, ratio $\mathrm{CyL} /$ cephalothorax width 0.36 . Subtegulum visible in ventral view. PTA in central position, hooked, tip pointing in ventral-proximal direction, not reaching lateral margin of cymbium. Sperm duct symmetric, opening in 7 o'clock position. Conductor largely hidden behind embolus, in ventral view protruding at both sides of embolus. Embolus at transition from basal to distal part with distinctive prolateral bulge that projects above prolateral margin of bulb, embolus tip a thin, almost straight spur.

Epigyne-vulva (Figs 27-28). Epigyne distinctly wider than long. Median septum triangular, narrowed posteriorly, epigynal sutures straight. Epigynal grooves large. Posterior guide pockets exceptionally wide and well developed, anterior guide pockets externally moderately sclerotized, in dorsal view visible as voluminous pockets. Receptacula bagpipe-shaped, somewhat separated from epigastric furrow, not touching each other. Glandular heads in inner-distal position, pointing in lateral-distal direction.

Distribution and habitat. Only known from the type locality (Fig. 37), no information on habitat available.

\section{Halodromus patellaris (Wunderlich, 1987)}

Figs 1, 4, 9, 15, 29-32

Ebo patellaris Wunderlich, 1987: 261-262, figs 679-680 (description male, holotype not examined).

Ebo eremus Levy, 1999: 188, figs 22-23 (description female). Syn. n. - Levy 2007: 19, figs $47-48$.

Material examined. CANARY ISLANDS: Lanzarote: $1 \overbrace{}^{\lambda}, 2 q$, Playa Famara, dunes, $29^{\circ} 67^{\prime} \mathrm{N}, 13^{\circ} 33^{\prime} \mathrm{W}$, March, leg. J. Wunderlich (CJW). TUNISIA: Kairouan: 2 + , salt

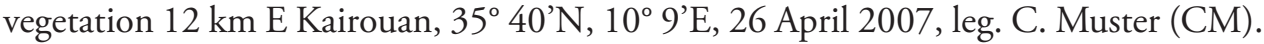
Monastir: $12{ }^{\wedge}, 10$ ㅇ, 2 juv., salt marsh near Monastir Airport, $35^{\circ} 45^{\prime} \mathrm{N}, 10^{\circ} 47^{\prime} \mathrm{E}, 27$ April 2007, leg. C. Muster (CM).

Diagnosis. Males are characterized by the triangular shape of the patellar apophysis and the small, narrow PTA (Figs 29-30), females by the parallel anterior guide pockets (Fig. 31).

Description. Measurements. Largest species of the genus. Male $(\mathrm{n}=5)$ : total length 3.26 (2.9-3.7), CL 1.54 (1.45-1.7), CW 1.62 (1.55-1.75), ClyH 0.28 (0.240.34), OL 1.88 (1.55-2.2), OW 1.47 (1.15-1.7). Leg I 7.08 (6.55-7.55) [1.98, 0.67, 
1.94, 1.53, 0.96], FemII 2.91 (2.75-3.0). Eye sizes and interdistances: AME 0.11, PME 0.08, AME-AME 0.13, AME-ALE 0.052, PME-PME 0.23, PME-PLE 0.14, ALE-PME 0.16. Pedipalp: PFem 0.69 (0.64-0.75), PPat 0.26 (0.24-0.27), PatApo 0.18 (0.14-0.20), PTib 0.27 (0.24-0.28), CyL 0.71 (0.68-0.74), CyW 0.41 (0.38$0.44)$. AME size index: 0.07 (0.067-0.074). PME interdistance index: 1.63 (1.5-1.81). Clypeus height index: 0.17 (0.16-0.21). Leg II length index: 1.48 (1.45-1.53).

Female $(\mathrm{n}=5)$ : total length $3.16(2.9-3.5)$, CL $1.27(1.05-1.45)$, CW 1.4 (1.15-1.6), ClyH 0.23 (0.18-0.27), OL 2.09 (1.8-2.3), OW 1.87 (1.6-2.1). Leg I 5.16 (4.2-5.9) [1.56, $0.55,1.35,1.05,0.65]$, FemII 2.29 (1.95-2.6). Eye sizes and interdistances: AME 0.11, PME 0.07, AME-AME 0.1, AME-ALE 0.04, PME-PME 0.2, PME-PML 0.11, ALEPME 0.12. AME size index: 0.076 (0.067-0.087). PME interdistance index: 1.81 (1.651.97). Clypeus height index: 0.16 (0.15-0.18). LegII length index: 1.47 (1.39-1.56).

Colour. Dorsal shield of prosoma (Fig. 15) brown with bright orange-brown median band that extends to posterior margin, allatal stripes discontinuous, metadiscus a whitish V-sign, mesodiscus with characteristic pattern. Clypeus with a rectangular beige area (Fig. 9), chelicerae brown with black spots. Sternum whitish with dots and brown patches at the margin. Legs orange-brown, intensely mottled and with double annula-

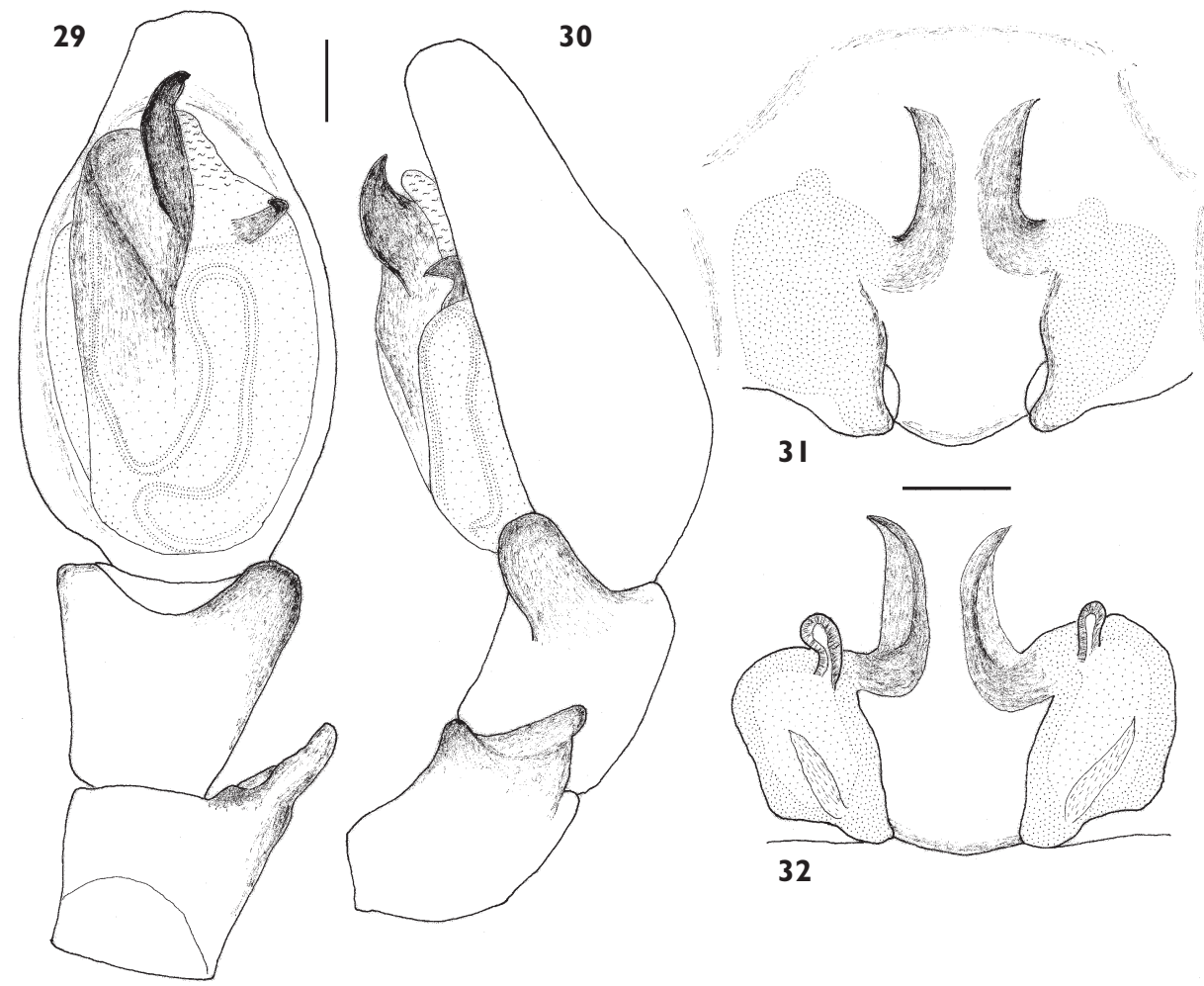

Figures 29-32. Halodromus patellaris from Monastir. 29-30 Left male palp (29 ventral, 30 retrolateral) 3I Epigyne, ventral 32 Vulva, dorsal. Scale line $=0.1 \mathrm{~mm}$. 
tions at femora, threefold annulations at tibiae and single, weak annulations at metatarsi. Opisthosoma densely covered with whitish pubescence, interspersed with dark setulae. Dorsum grey with conspicuous black cardiac mark, flanks darkish, in posterior half with four to five chevrons and two lateral dark patches. Venter greyish marbled.

Pedipalp (Figs 1, 29-30). Patellar apophysis relatively short, less than two thirds the length of tibia, in ventral view narrow, in lateral view triangular, with small but distinct bulge at basis of ventral margin. Tibia with broad, rounded RTA. Cymbial tip short, less than one fifth of $\mathrm{CyL}$, broadly rounded. Cymbium length $(\mathrm{CyL})$ 0.68-0.74, width (CyW) 0.38-0.44, ratio $\mathrm{CyL} /$ cephalothorax width 0.44-0.46. Subtegulum visible in ventral view. PTA a small narrow hook, directed retrolaterally, its tip pointing in ventral direction. Sperm duct forming an elongate, asymmetric loop in retrolateral half of tegulum, opening in 8:30 o'clock position. Conductor partly hidden behind embolus, in ventral view visible at retrolateral side of embolus. Embolus clearly divided in basal and distal embolus. Basal embolus with prolateral-distal bulge and curved keel at ventral side. Distal embolus stout, curved to retrolateral side.

Epigyne-vulva (Figs 31-32). Epigyne wider than long. Median septum almost quadrangular, epigynal sutures short. Epigynal grooves covered by lateral plates. Posterior guide pockets small, anterior guide pockets prominent, heavily sclerotized, with almost parallel slits, extending anteriorly far beyond receptacula. Receptacula at epigastric furrow, separated from each other by their diameter. Glandular heads in innerdistal position, with short ducts pointing in lateral-distal direction.

Remarks. Due to the serious illness of Dr Gershom Levy I failed to receive the type series of Ebo eremus Levy from the Hebrew University of Jerusalem for examination. However, the species was sufficiently characterized by Levy $(1999,2007)$ to propose synonymy with Halodromus patellaris (Wunderlich).

Distribution and habitat. The species is known from the eastern Canary Islands Fuerteventura (Wunderlich 1987, 1992) and Lanzarote, from the Negev desert in southern Israel (Levy 1999, 2007), and from Tunisia (Fig. 37). All specimens from Israel were taken using pitfall traps. The specimens from Tunisia were beaten from prostrate halophytic shrubs in saline habitats at both coastal and inland sites. They were perfectly camouflaged in the dense vegetation.

\section{Halodromus patellidens (Levy, 1977)}

Figs 13, 33-36

Ebo patellidens Levy, 1977: 210-212, figs 36-39 (description male, female; holotype not examined). - Wunderlich 1992: 504, figs 808f-g.

Material examined. ALGERIA: Biskra: $10^{\top}$, Biskra, $34^{\circ} 51^{\prime} \mathrm{N}, 5^{\circ} 44^{\prime} \mathrm{E}$, leg. E. Simon (MNHN ES 12383). CABO VERDE: Sal: 1ㅇ, Santa Maria, $16^{\circ} 36^{\prime} \mathrm{N}, 22^{\circ} 54^{\prime} \mathrm{W}, 29$ March 1988, leg. M. Schmidt (SMF 37380); 1의, same locality (SMF 38000); $10^{\Uparrow}$, same locality, 3 April 1994, leg. M. Schmidt (SMF 38018). KUWAIT: Al Ahmadi: 2 , 
1 juv., Kubbar Island, $29^{\circ} 04^{\prime} \mathrm{N}, 48^{\circ} 29^{\prime} \mathrm{E}, 17$ March 1988, leg. W. Büttiker (NHMB); 1 , , same data, leg. W. Al-Bouty (NHMB). SAUDI ARABIA: Eastern Province: 1 , Al-Khobar, $26^{\circ} 17^{\prime} \mathrm{N}, 50^{\circ} 12^{\prime} \mathrm{E}, 12$ January 1983, leg. E. Heiss (CTh). TUNISIA: Tataouine: 1 , , Bir Thelethine $S$ Tataouine, in Salicornia and tamarisk bushes, $32^{\circ}$ $55^{\prime} \mathrm{N}, 10^{\circ} 27^{\prime} \mathrm{E}, 18$ December 2000, leg. R. Bosmans (CB). YEMEN: 'Adan: $60^{\lambda}, 8$ 을 Aden, $12^{\circ} 48^{\prime} \mathrm{N}, 45^{\circ} 02^{\prime} \mathrm{E}, 1889$, leg. E. Simon $\left(1{ }^{\lambda}, 1\right.$ 우 MNHN ES 10779; $5{ }^{\lambda}, 7$ 우 MNHN ES 19099). Hadramowt: $20^{\wedge}, 4$ juv., Island Perim, $12^{\circ} 65^{\prime} \mathrm{N}, 43^{\circ} 41^{\prime} \mathrm{E}$, leg. F. Jousseaumme (MNHN ES 10818).

Diagnosis. Males are characterized by the exceptionally large patellar apophysis and by the large PTA that projects beyond the retrolateral margin of the cymbium (Figs 33-34). Females are recognizable by the coiled anterior guide pockets and the shape of the receptacula (Figs 35-36).

Description. Measurements. Male ( $\mathrm{n}=5$ ): total length 2.89 (2.65-3.2), CL 1.37 (1.25-1.45), CW 1.47 (1.35-1.55), ClyH 0.24 (0.22-0.27), OL 1.65 (1.5-1.8), OW 1.33 (1.2-1.6). Leg I 6.11 (5.9-6.3) [1.78, 0.63, 1.63, 1.28, 0.81], FemII 2.53. Eye sizes and interdistances: AME 0.12, PME 0.07, AME-AME 0.1, AME-ALE 0.04, PME-PME 0.22, PME-PLE 0.11, ALE-PME 0.14. Pedipalp: PFem 0.58 (0.5-0.6), PPat 0.23 (0.20.25), PatApo 0.32 (0.26-0.36), PTib 0.3 (0.28-0.32), CyL 0.65 (0.6-0.68), CyW 0.36 (0.35-0.36). AME size index: 0.08 (0.077-0.083). PME interdistance index: 1.83 (1.752.0). Clypeus height index: 0.17 (0.15-0.18). LegII length index: 1.46 (1.41-1.53).

Female $(\mathrm{n}=5)$ : total length $3.16(2.9-3.5)$, CL $1.27(1.05-1.45)$, CW $1.4(1.15-$ 1.6), ClyH 0.23 (0.18-0.27), OL 2.09 (1.8-2.3), OW 1.87 (1.6-2.1). Leg I 5.16 (4.25.9) $[1.56,0.55,1.35,1.05,0.65]$, FemII 2.29 (1.95-2.6). Eye sizes and interdistances: AME 0.11, PME 0.07, AME-AME 0.1, AME-ALE 0.04, PME-PME 0.2, PMEPML 0.11, ALE-PME 0.12. AME size index: 0.076 (0.067-0.087). PME interdistance index: 1.81 (1.65-1.97). Clypeus height index: 0.16 (0.15-0.18). LegII length index: 1.47 (1.39-1.56).

Colour. Dorsal shield of prosoma (Fig. 13) brown with bright orange-brown median band that extends to posterior margin, allatum with dark radiating stripes and whitish patches along longitudinal allatal stripes, metadiscus a whitish V-sign, mesodiscus with characteristic pattern. Clypeus with a beige area, chelicerae orange brown with dark spots. Sternum whitish with numerous small spots. Legs orange-brown, intensely mottled and with double annulations at femora and threefold annulations at tibiae. Opisthosoma densely covered with whitish pubescence, interspersed with dark setulae. Dorsum grey with conspicuous black cardiac mark that broadens in posterior third, followed by two dark spots and some partially fused chevrons, flanks darkish, in posterior half with four to five chevrons and two lateral dark patches. Venter greyish marbled with three faint longitudinal stripes.

Pedipalp (Figs 33-34). Patella exceptionally long and voluminous, longer than tibia. Tibia with almost rectangular processing RTA with rounded tip. Cymbial tip relatively short, less than one fourth of CyL. Cymbium length $(\mathrm{CyL})$ 0.6-0.68, width $(\mathrm{CyW})$ 0.35-0.36, ratio CyL/cephalothorax width 0.4-0.47. Subtegulum visible in ventral view. Anterior border of tegulum indistinct, PTA large, laminar, projecting be- 
yond retrolateral margin of cymbium, its tip pointing in ventral direction. Sperm duct forming an elongate, asymmetric loop in retrolateral half of tegulum, opening in 8 o'clock position. Conductor a narrow membrane at retrolateral side of embolus, mostly visible in ventral view. Embolus broadly merged with tegulum, near distal embolus with prolateral bulge, distal embolus stout, pointing in a retrolateral-distal direction.

Epigyne-vulva (Figs 35-36). Epigyne slightly wider than long. Median septum triangular, but margins covered by lateral plates, thus epigynal sutures and epigynal grooves invisible in ventral view, margins of lateral plates sigmoid. Posterior guide pockets small, indistinct, anterior guide pockets conspicuously coiled structures, in dorsal view covered by receptacula. Receptacula widely separated from epigastric furrow, with median insection, distal parts in close contact. Glandular heads in inner -distal position, pointing inwards.

Remarks. Due to the serious illness of Dr Gershom Levy I failed to receive the type series of Ebo patellidens Levy from the Hebrew University of Jerusalem for examination. However, the detailed figures provided by Levy (1977) allow the unequivocal identification of the examined material with this species.

Distribution and habitat. The available evidence suggests that $H$. patellidens is rather widespread in the Middle East, but also along the north-African coast (Fig. 37).
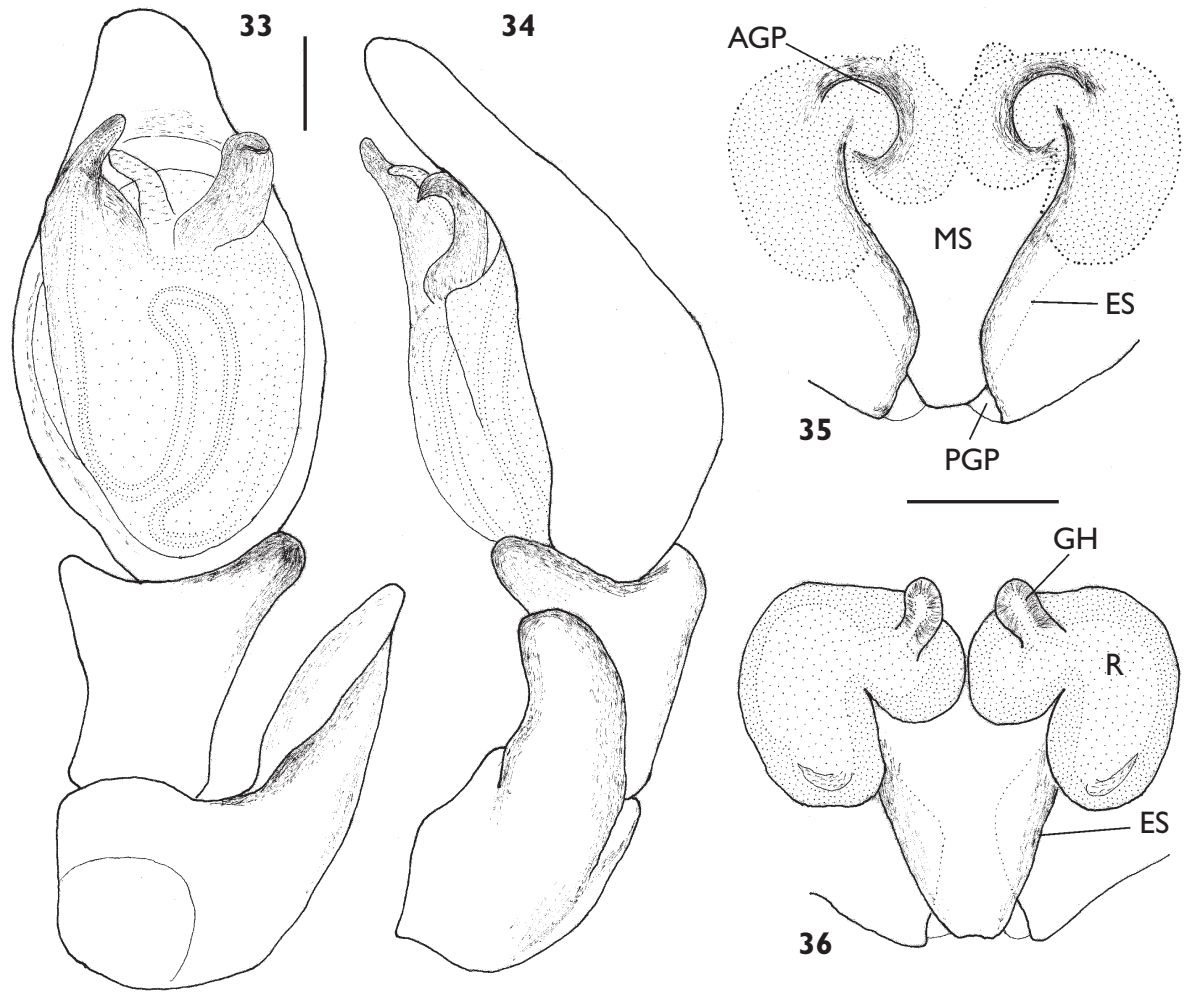

Figures 33-36. Halodromus patellidens from Aden. 33-34 Left male palp (33 ventral, 34 retrolateral) 35 Epigyne, ventral 36 Vulva, dorsal. Scale line $=0.1 \mathrm{~mm}$. 


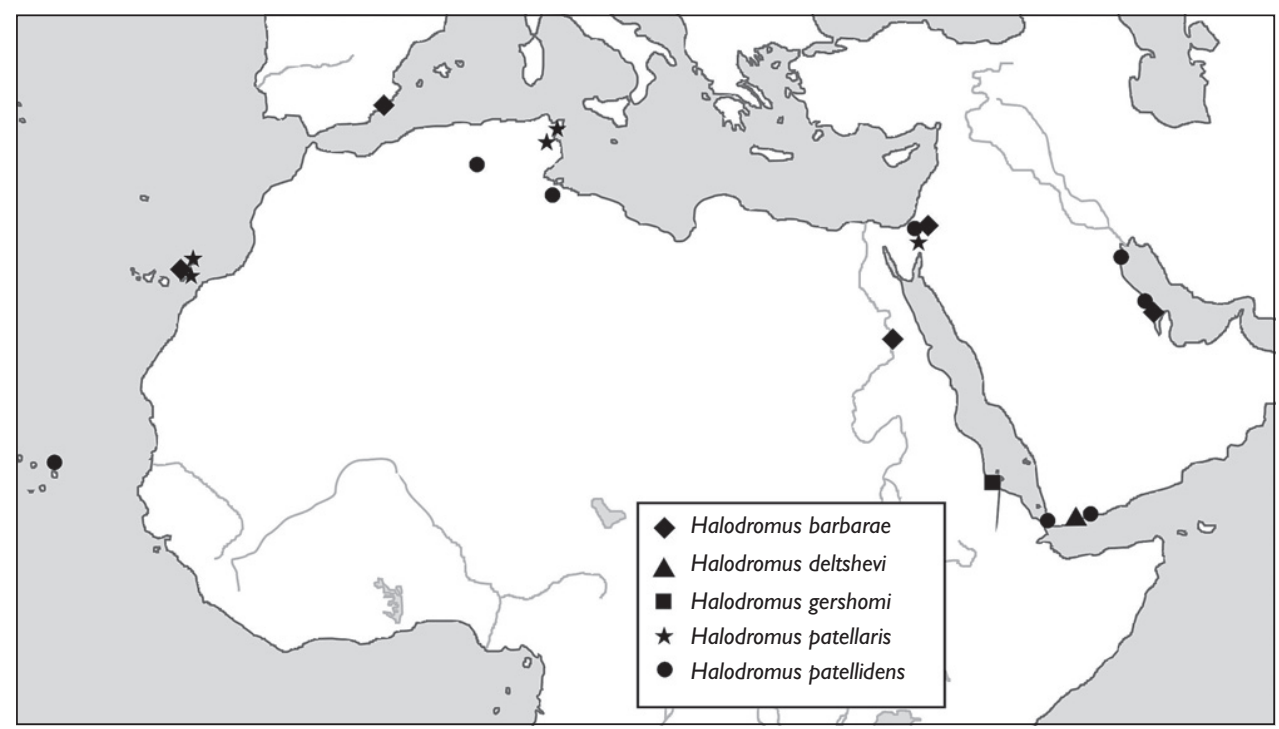

Figure 37. Distribution of Halodromus species.

The occurrence of $H$. patellidens on the Cape Verde islands (Schmidt 1990; Schmidt and Krause 1995) was doubted by Wunderlich (1992: 504-505), yet it could be confirmed through examination of material from the SMF. On the other hand, the species has not been recorded from the Canary Islands. The record from Fuerteventura (Schmidt 1990) results from the erroneous synonymization with $H$. patellaris (already rejected by Wunderlich 1992: 504). Habitat information is scarce, but Schmidt and Krause (1995) collected the species from halophytes.

\section{Incertae sedis}

The following species, originally described in Ebo, show striking differences in genitalic and/or somatic characters compared to Ebo latithorax and its congeners from North America. However, these species are difficult to place in the system, and at the current state of knowledge I refrain from suggesting new generic assignments.

\section{Ebo bharatae Tikader, 1965}

Ebo bharatae Tikader, 1965: 278-279, figs 2a-c. - Tikader 1971: 67, figs 18a-c; Tikader 1980: 179, figs 249-251.

Remarks. No information on leg spination and morphometric indices is given in Tikader $(1965,1971,1980)$. Without re-examination of the type series the relationship of this species cannot be inferred. 
Ebo carmineus Mello-Leitáo, 1944

Ebo carmineus Mello-Leitão, 1944: 362-363, fig. 55.

Remarks. Mello-Leitâo $(1942,1943,1944)$ described three Ebo species from South America. From the information given in the original descriptions I feel unable to deduce their correct generic placement. With five pairs of ventral spines on tibia I and four pairs on the metatarsus the leg spination in Ebo carmineus it is strikingly different from North American Ebo, suggesting generic misplacement.

\section{Ebo distinctivus Lyakhov, 1992}

Ebo distinctivus Lyakhov, 1992: 148-149, figs 1-4.

Material examined. RUSSIA: Altai Republic: $1 \delta^{\lambda}$, vicinity of Kosh-Agatch, Kurai Mt.

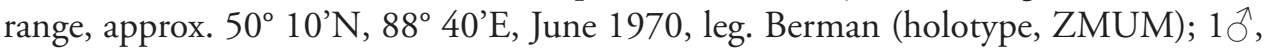
same data (paratype, SZMN); 1 9 , same locality, 26 May 1970, leg. A. P. Kononenko (allotype, epigynum missing, ZMUM).

Remarks. The leg spination pattern and other features preclude the retention of this species in Ebo. Several morphological characters (configuration of embolus, lack of PTA, leg spination pattern) suggest a sister-group relationship with Titanebo. On the other hand, it differs from Titanbeo in the reduced tibial apophyses, and the presence of an apical pair of ventral spines on the tibiae is a unique character.

\section{Ebo fuscus Mello-Leitáo, 1943}

Ebo fuscus Mello-Leitão, 1943: 118-119, fig. 21.

Remarks. See E. carmineus.

\section{Ebo meridionalis Mello-Leitáo 1942}

Ebo meridionalis Mello-Leitão 1942: 405-407, figs 29-30.

Remarks. See E. carmineus. 


\section{Discussion}

A close examination of morphometrics, leg spination as well as male and female genitalia has clearly demonstrated the polyphyletic character of Ebo as hitherto delineated. The Nearctic subgenera Ebo and Titanebo are distinct enough to deserve genus rank. Their occurrence in the Old World remains uncertain, as the placement of Ebo bharatae from India and Ebo distinctivus from the Altai Mountains requires further studies. The remaining species from the Old World are either transferred to the Philodromus histrio group or to the new genus Halodromus, which is characterized by at least one putative autapomorphy, the long apophysis at the patella of the male palp. The presence of a patellar apoyphsis is very unusual within Philodromidae, only males of the Philodromus subgenus Locupletes Schick, 1965 also bear a short retrolateral projection at the palpal patella (Schick 1965). The proposed transfers are a contribution to the effort of making more genera of Philodromidae monophyletic. However, phylogenetic relationships among the Ebo-like philodromid spider genera remain largely unresolved, as different character sets provide conflicting evidence. Concerning male genitalic traits, Ebo and Titanebo appear closely related. Leg spination is similar in Titanebo, Halodromus and Rhysodromus, but strikingly different in Ebo. Female genitalia are unique in Titanebo, but almost indistinguishable between Halodromus and Rhysodromus. Morphological and biogeographic considerations suggest a rather close relationship of Halodromus and Rhysodromus, but it is not clear whether Halodromus is sister to Rhysodromus or rather a distal clade within Rhysodromus. Reconstructions are further hampered by the problematic delineation of Rhysodromus/the Philodromus histrio group. In the limits of Szita and Logunov (2008) it is most probably a paraphyletic assemblage.

The Ebo-like philodromid genera recognized in this study have the following biogeographic origins. Schick (1965) identified Ebo as an "Austral element", with a distribution centre south of the Nearctic coniferous forests. Ebo s. str. is widely distributed in temperate North America, while Titanebo is an eremial element with primary centre of distribution in the deserts of the southwestern Nearctic ("Sonoran element"). Halodromus is also allocated to the eremial fauna, with a distribution centre in the Afro-SyroEremial regions south of the Mediterranean. A remarkable result of this study is the uncovering of the vast Afroeremial distribution of several species that have been considered narrow endemics of Israel or the Canary Islands respectively. Rhysodromus species are widely distributed from boreal to eremial regions in the Holarctic. The highest diversity is recorded from the eastern Palaearctic (Szita and Logunov 2008), but a better knowledge of the African and South-Asian philodromid fauna may result in deeper insights.

\section{Acknowledgements}

This research received support from the SYNTHESYS Project http://www.synthesys. info/ which is financed by European Community Research Infrastructure Action under the FP6 'Structuring the European Research Area' Programme. The hospitality 
of the host Christine Rollard (MNHN) contributed to the success of this project. I would like to thank Peter Michalik (University of Greifswald) for access to technical resources in his department and for taking the SEM photographs. This study would not have been possible without the generous loan of specimens from the following persons and institutions: Robert Bosmans (CB), Efrat Gavish-Regev (TAU), Ambros Hänggi (NHMB), Peter Jäger and Julia Altmann (SMF), Barbara Thaler-Knoflach (CTh), Norman Platnick (AMNH), Christine Rollard and Elise-Anne Leguin (MNHN), and Jörg Wunderlich (CJW). Access to copies of rare and old literature was given by courtesy of Peter Jäger (SMF). Thanks are due to Christophe Herve (MNHN) for his help with identifying labels and localities from the Simon collection. I am deeply indebted to Dmitri Logunov (the Manchester Museum) for the loan of comparative material, fruitful discussion and comments on an earlier draft. The comments of two anonymous referees helped to improve a former version of the manuscript.

\section{References}

Cokendolpher JC (1978) A new species of Ebo from north-central Texas (Araneida: Philodromidae). Journal of Arachnology 6: 227-229.

Dondale CD, Redner JH (1975) The fuscomarginatus and histrio groups of the spider genus Philodromus in North America (Araneida: Thomisidae). Canadian Entomologist 107: 369-384.

Dondale CD, Redner JH (1978) The insects and arachnids of Canada, Part 5. The crab spiders of Canada and Alaska, Araneae: Philodromidae and Thomisidae. Research Branch, Agriculture Canada, Publication 1663: 1-255.

Evenhuis NL (2007) The insect and spider collections of the world webside. http://hbs.bishopmuseum.org/codens/codens-r-us.html [accessed 15.II.2009]

Gertsch WJ (1933) New genera and species of North American spiders. American Museum Novitates 636: 1-28.

Keyserling E (1884) Neue Spinnen aus Amerika, V. Verhandlungen der zoologisch-botanischen Gesellschaft in Wien 33: 649-684.

Kraus O (1984) Hoyer's Gemisch statt Polyvinyl-Lactophenol. Mikrokosmos 2: 54-55.

Levy G (1977) The philodromid spiders of Israel (Araneae: Philodromidae). Israel Journal of Zoology 26: 193-229.

Levy G (1999) New thomisid and philodromid spiders (Araneae) from southern Israel. Bulletin of the British Arachnological Society 11: 185-190.

Levy G (2007) Calommata (Atypidae) and new spider species (Araneae) from Israel. Zootaxa 1551: 1-30.

Lyakhov OV (1992) Ebo distinctivus sp.n. (Araneae, Philodromidae) from the Altai. Zoologicheskiy Zhurnal 71: 147-149.

Mello-Leitão CF de (1942) Arañas del Chaco y Santiago del Estero. Revista del Museo de la La Plata (N.S., Zool.) 2: 381-426.

Mello-Leitão CF de (1943) Arañas nuevas de Mendoza, La Rioja y Córdoba colectadas por el Professor Max Birabén. Revista del Museo de la La Plata (N.S., Zool.) 3: 101-121. 
Mello-Leitão CF de (1944). Arañas de la provincia de Buenos Aires. Revista del Museo de la La Plata (N.S., Zool.) 3: 311-393.

Muster C, Bosmans R, Thaler K (2007) The Philodromus pulchellus-group in the Mediterranean: Taxonomic revision, phylogenetic analysis and biogeography (Araneae: Philodromidae). Invertebrate Systematics 21: 39-72.

Muster C (2009) Phylogenetic relationships within Philodromidae, with a taxonomic revision of the Philodromus subgenus Artanes in the western Palearctic (Arachnida: Araneae). Invertebrate Systematics 23: 135-169.

Ono H (1988) A revisional study of the spider family Thomisidae (Arachnida, Araneae) of Japan. National Science Museum, Tokyo, Japan, 252 pp.

Platnick NI (1972) Notes on the pepinensis group of the crab spider genus Ebo (Araneae: Thomisidae). Psyche 79: 58-60.

Sauer RJ, Platnick NI (1972) The crab spider genus Ebo (Araneida: Thomisidae) in the United States and Canada. Canadian Entomologist 104: 35-60.

Schick RX (1965). The crab spiders of California (Araneae, Thomisidae). Bulletin of the American Museum of Natural History 129: 1-180.

Schmidt G (1990) Zur Spinnenfauna der Kanaren, Madeiras und der Azoren. Stuttgarter Beiträge zur Naturkunde A (Biologie) 451: 1-46.

Schmidt G, Krause RH (1995) Weitere Spinnen von Cabo Verde. Entomologische Zeitschrift 105: 365-380.

Schmidt G, Krause RH (1996) Weitere Spinnenfunde von den Kanarischen Inseln, hauptsächlich von Fuerteventura und Lobos (Arachnida: Araneae). Faunistische Abhandlungen Staatliches Museum für Tierkunde Dresden 20: 259-273.

Simon E (1895) Histoire naturelle des araignées. Roret, Paris, France, Vol. 1, pp. 761-1084.

Szita E, Logunov DV (2008) A review of the histrio group of the spider genus Philodromus Walckenaer, 1826 (Araneae, Philodromidae) of the eastern Palaearctic region. Acta Zoologica Academiae Scientiarum Hungaricae 54: 23-73.

Tikader BK (1965) On some new species of spiders of the family Thomisidae from India. Proceedings of the Indian Academy of Sciences 61: 277-289.

Tikader BK (1971) Revision of Indian crab spiders. Memoirs of the zoological survey of India 15: $1-90$.

Tikader BK (1980) Thomisidae (Crab-spiders). Fauna India (Araneae) 1: 1-247.

Wunderlich J (1987) Die Spinnen der Kanarischen Inseln und Madeiras: Adaptive Radiation, Biogeographie, Revisionen und Neubeschreibungen. Triops, Langen, Germany, 435 pp.

Wunderlich J (1992) Die Spinnen-Fauna der Makaronesischen Inseln: Taxonomie, Ökologie, Biogeographie und Evolution. Beiträge zur Araneologie 1: 1-619. 